\title{
Optimization of biogas supply networks considering multiple objectives and auction trading prices of electricity
}

\author{
Jafaru Musa Egieya ${ }^{1,2}$, Lidija Čuček $^{3^{*}}$ D, Klavdija Zirngast ${ }^{3}$, Adeniyi Jide Isafiade ${ }^{2}$ and Zdravko Kravanja ${ }^{3}$
}

\begin{abstract}
This contribution presents an hourly-based optimization of a biogas supply network to generate electricity, heat and organic fertilizer while considering multiple objectives and auction trading prices of electricity. The optimization model is formulated as a mixed-integer linear programming (MILP) utilizing a four-layer biogas supply chain. The model accounts for biogas plants based on two capacity levels of methane to produce on average $1 \pm 0.1 \mathrm{MW}$ and $5 \pm 0.2$ MW electricity. Three objectives are put forward: i) maximization of economic profit, ii) maximization of economic profit while considering cost/benefits from greenhouse gas $(\mathrm{GHG})$ emissions (economic ${ }^{+\mathrm{GHG}}$ profit) and iii) maximization of sustainability profit. The results show that the economic profit accrued on hourly-based auction trading prices is negative (loss), hence, four additional scenarios are put forward: i) a scenario whereby carbon prices are steadily increased to the prevalent eco-costs/eco-benefits of global warming; ii) a scenario whereby all the electricity auction trading prices are multiplied by certain factors to find the profitability breakeven factor, iii) a scenario whereby shorter time periods are applied, and investment cost of biogas storage is reduced showing a relationship between cost, volume of biogas stored and the variations in electricity production and (iv) a scenario whereby the capacity of the biogas plant is varied from $1 \mathrm{MW}$ and $5 \mathrm{MW}$ as it affects economics of the process. The models are applied to an illustrative case study of agricultural biogas plants in Slovenia where a maximum of three biogas plants could be selected. The results hence present the effects of the simultaneous relationship of economic profit, economic ${ }^{+G H G}$ profit and sustainability profit on the supply and its benefit to decision-making.
\end{abstract}

Keywords: Biogas production, Auction trading prices of electricity, Supply network optimization, Multiple objectives, Economic profitability

\section{Introduction}

In December 2015, over 190 countries across the globe acceded to employing activities and technologies that minimize the effects of global climate change [1]. Among the technologies considered is to increase the utilization of biomass-derived energy sources (also called bioenergy). Furthermore, in Yue et al. [2], utilising bioenergy has the potential to: bolster energy security in economies not having fossil energy sources; mitigate the effects of variable fossil energy prices and availability; improve waste management concerning exploiting food wastes to produce bioenergy thereby creating wealth. A

\footnotetext{
* Correspondence: lidija.cucek@um.si

${ }^{3}$ Faculty of Chemistry and Chemical Engineering, University of Maribor,

Smetanova ulica 17, 2000 Maribor, Slovenia

Full list of author information is available at the end of the article
}

more recent study in Hegnsholt et al. [3] shows that on average $33 \%$ of total annual worldwide food production $\left(1.6 \cdot 10^{9} \mathrm{t} / \mathrm{y}\right)$ costing $1.2 \cdot 10^{12} \$ / \mathrm{y}$ goes to waste. This massive loss of food is a subject of concern; it is unacceptable, and severely hampers the United Nations' Sustainable Development Goals target to cut the food loss and waste by $50 \%$ in 2030 [4].

Consequently, against this backdrop, some countries have laid down policies to accelerate the increased integration of bioenergy in their economy. For example, the national government of India in 2009 adopted a policy to produce about $14 \cdot 10^{5} \mathrm{t} / \mathrm{y}$ of biofuels to meet $20 \%$ blending of biofuels used in the transportation fuels by the year 2020 [5]. It is noteworthy that this policy only considers the use of non-edible feedstock retrieved from lands unsuitable for agriculture to prevent food versus fuel conflicts. In another case, the

(c) The Author(s). 2020 Open Access This article is distributed under the terms of the Creative Commons Attribution 4.0 International License (http://creativecommons.org/licenses/by/4.0/), which permits unrestricted use, distribution, and 
government of Ghana enacted a biofuels policy to substitute petroleum fuels with $10 \%$ biofuels by 2020 and a further increase to $20 \%$ biofuels incorporation by 2030 [6]. The Ghana government included additional policies directed to exploiting energy from wastes such as municipal, industrial and agricultural wastes [6]. India and Ghana are generally described as developing countries but in other situations, developed countries have also instituted policies to accelerate bioenergy exploitation. The USA, through the Energy Independence and Security Act (EISA) of 2007, sets an annual production target of $116 \cdot 10^{6} \mathrm{t} / \mathrm{y}$ of biofuels by 2022 [2]. Moreover, the EU in another case aims to substitute $10 \%$ of the transportation fuel in all EU countries with biofuels by 2020 [7]. Alternatively, it is interesting to note that China places bold targets to harness biomass energy from disparate sources implementable on five-year plans. For example, its current policy (13th five-year spanning 2016-2020) indicates that on or before the year 2020, the rate of utilization of energy derived from biomass should exceed $58 \cdot 10^{6} \mathrm{t} / \mathrm{y}$ of standard coal while biogas employed for cooking should reach $80 \cdot 10^{6} \mathrm{~m}^{3}$ and electricity generated from the same biogas should be at least $500 \mathrm{MWe}$ [8].

With these policies in place, implementing them has presented some challenges. In Hegnsholt [3], designing, modelling and effecting robust supply chains is suggested as a veritable tool required to bolster bioenergy integration in any economy. In effect, all bioenergy production supply chains consist of several actors (farmers/ waste collection and acquisition centres, production/ conversion facilities and different demand zones) which are constantly interacting [9]. These actors are usually present in different geographical locations which necessitate producing bioenergy products in a timely fashion to meet certain demands. A closer examination of these actors shows the following:

i. Farmers/waste collection centres - Usually contain feedstocks that are described as firstgeneration (1G), second-generation $(2 G)$ and thirdgeneration (3G) [10]. The $1 \mathrm{G}$ feedstocks (starch-, sugar- and oil-based) are edible foods which have led to the rise in prices of food due to competition in accessing limited resources (like land) to produce bioenergy products [1]. Today, majority of bioenergy investments are based on $1 \mathrm{G}$ feedstocks (such as sugarcane, corn and palm oil) whereby most commercialized bioenergy production technologies also utilize the $1 \mathrm{G}$ feedstocks [11]. On the other hand, $2 \mathrm{G}$ feedstocks are those which contain lignocellulosic and waste materials (like manure, municipal wastes, straw or even bagasse) and unlike the $1 \mathrm{G}$ feedstocks, these feedstocks are not edible. They have enough potential to produce bioenergy while simultaneously not affecting the cost and availability of food crops. However, the 3G feedstocks usually referred to as algae, on average produce more energy per area than any other generation of feedstocks but today, 3G feedstock are only used on a laboratory scale.

ii. Production/Conversion Technologies - There are three groups of biomass conversion technologies currently in use today and these are thermo-chemical conversion (direct combustion, liquefaction, gasification, pyrolysis), physico-chemical conversion (transesterification) and biochemical conversion (anaerobic digestion, fermentation, composting).

iii. Demand centres - These centres are usually the locations whereby the bioenergy products are either blended with conventional fossil fuels for onward use or directly consumed.

As stated earlier, these bioenergy products must be delivered to meet certain demands in a timely fashion. The demand constraints placed on bioenergy may be set on economic, environmental and/or social objectives or each of the individual objectives [2]. Hence, as a backdrop of the above context, the following section introduces some of the recent works carried out in the modelling and optimization of bioenergy or biogas production supply chains which is the focus of this work.

\section{Review of literature on biogas/bioenergy supply chain optimization}

In recent years, there has been a considerable increase in research on bioenergy supply chain optimization. These studies have generally been geared towards individually meeting economic, environmental, social objectives or a combination of the objectives on certain timescales. For example, El-Halwagi et al. [12] simultaneously modelled the minimization of risk (as a metric of the social objective) and total annual cost (TAC) in the supply chain of biorefining system applied to bio-hydrogen production. Zirngast et al. [13] proposed four-step methodology for flexible supply network synthesis under uncertainty applied to biogas production where economic, eco- and viability profits were maximized. Emara et al. [14] developed a MILP model, using C\#, MATLAB and Excel Solver, to minimize the TAC in the supply chain of biofuel and chemicals from waste cooking oil. Ivanov et al. [15] researched the supply chain production of bioethanol from $1 \mathrm{G}$ and $2 \mathrm{G}$ feedstocks whereby TAC and greenhouse gas (GHG) emissions are minimized and the number of jobs created maximized. The economic and environmental optimization of biogas supply chain (maximization of annual profit and GHG emission savings) has been performed using MILP optimization 
approach and applied for a region in Mexico by DíazTrujillo et al. [16].

Several optimization studies have been carried out over hourly, daily, monthly and yearly timeframes. For instance, Egieya et al. [17] modelled a multi-month and multi-year MILP model for bioelectricity supply chain production in Slovenia. Mousavi Ahranjani et al. [18], in a more recent study, developed a fuzzy programming model for bioethanol supply chain network design over a 10 years' planning horizon in Iran. Čuček et al. [19] presented an optimally integrated supply chain network to produce bioenergy from 1G, 2G, and 3G feedstocks monthly using a MILP model. Besides, Egieya et al. [20], in another study, employed a MILP model which proposes hourly, daily, and monthly generation of bioelectricity from biogas in Slovenia.

Some economic objective-based studies involve the minimization of TAC [15], others emphasize maximizing profit [21], while a few others maximized the net present value (NPV) of a supply chain [22]. Concerning environmental objectives, minimizing global warming potential, exemplified by limiting GHG emissions, is receiving the most attention [23]. Several supply chain optimization studies performed optimization of economic-environmental parts while social sustainability is less commonly addressed. It is the least understood sustainability pillar, thus also called "missing pillar" [24]. Social pillar is often qualitative by nature and it is challenging to build a single metric for social sustainability and to incorporate it into mathematical models. Some work has been done recently, e.g. by You et al. [25] who maximized the number of jobs created in a bioenergy production supply chain, El-Halwagi et al. [12] who modelled safety as a metric of the social objective and Zore et al. [26] who optimized social profit from various micro- and macroeconomic perspectives [27].

From the previous studies, it is found that only a few researchers considered shorter time-periods, such as hourly time periods, while the bulk of bioenergy supply chain optimization studies have concentrated on bioethanol and biodiesel production, with a limited few on biogas supply chains. In this work, beyond what has previously been done to the best of our knowledge, two biogas plant capacities (on average of about $1 \mathrm{MW}$ and $5 \mathrm{MW}$ capacity of electricity production) are considered, and an optimization is performed based on different economic and sustainability objectives simultaneously accommodating hourly, daily and monthly optimization basis and auction trading prices of electricity. An additional input to this study is the integration of biogas storage to enable simultaneous electricity production at higher prices with biogas storage at low electricity prices. Moreover, model size reduction techniques are implemented to shorten the computational time of each model.

\section{Problem statement}

A holistic supply network management comprising several agricultural feedstocks (with different harvesting periods, availability and prices), transport modes, conversion technologies, and products with various prices including hourly-based electricity prices, was considered. Egieya et al. [28] introduced the single objective function of economic profit maximization which has been opined in several quarters to be unsuitable for realistic complete analysis and synthesis of bioenergy supply chains/networks. In this respect, for the optimal design of biogas supply networks, other optimization criteria such as maximizing unburdening from GHG emissions (maximizing the profit from GHG emission unburdening) and including the sustainability profit maximization are therefore addressed, see Fig. 1.

Hence, the design problem entails the problem statement given in Egieya et al. [28] and the following additions:

- eco-costs [29] of feedstocks during harvesting and collection;

- eco-benefits [30] of feedstocks use;

- eco-costs/eco-benefits of intermediate and final products;

- eco-costs of transport modes;

- GHG emissions of feedstocks during harvesting and collection;

- GHG emissions of intermediate and final products generation;

- GHG emissions due to transport;

- avoided GHG emissions due to harmful feedstocks use and substitution of products [30];

- social costs and profits [26].

The objectives of the upgraded model are to maximize economic profit, maximize economic profit while including costs and benefits due to released and avoided GHG emissions in the biogas supply network on the other hand, and to maximize the sustainability profit. Four scenarios are performed to improve the applicability of the biogas supply network, such as:

- Increasing the price for GHG emissions from approximately $20 € / \mathrm{t}$ (as of 24 February 2019 [31]) or $26.6 \$ / t$ by using the conversion rate of $1.33 \$ / €$ (as used in $[17,20,28]$ to the value of eco-costs / benefits of global warming which is $116 € / t$ [32] or 154.28 \$/t (based on considered conversion);

- Multiplying the values of auction trading prices by certain factors to obtain the prices where biogas production becomes economically profitable. This scenario could provide answers to how much 


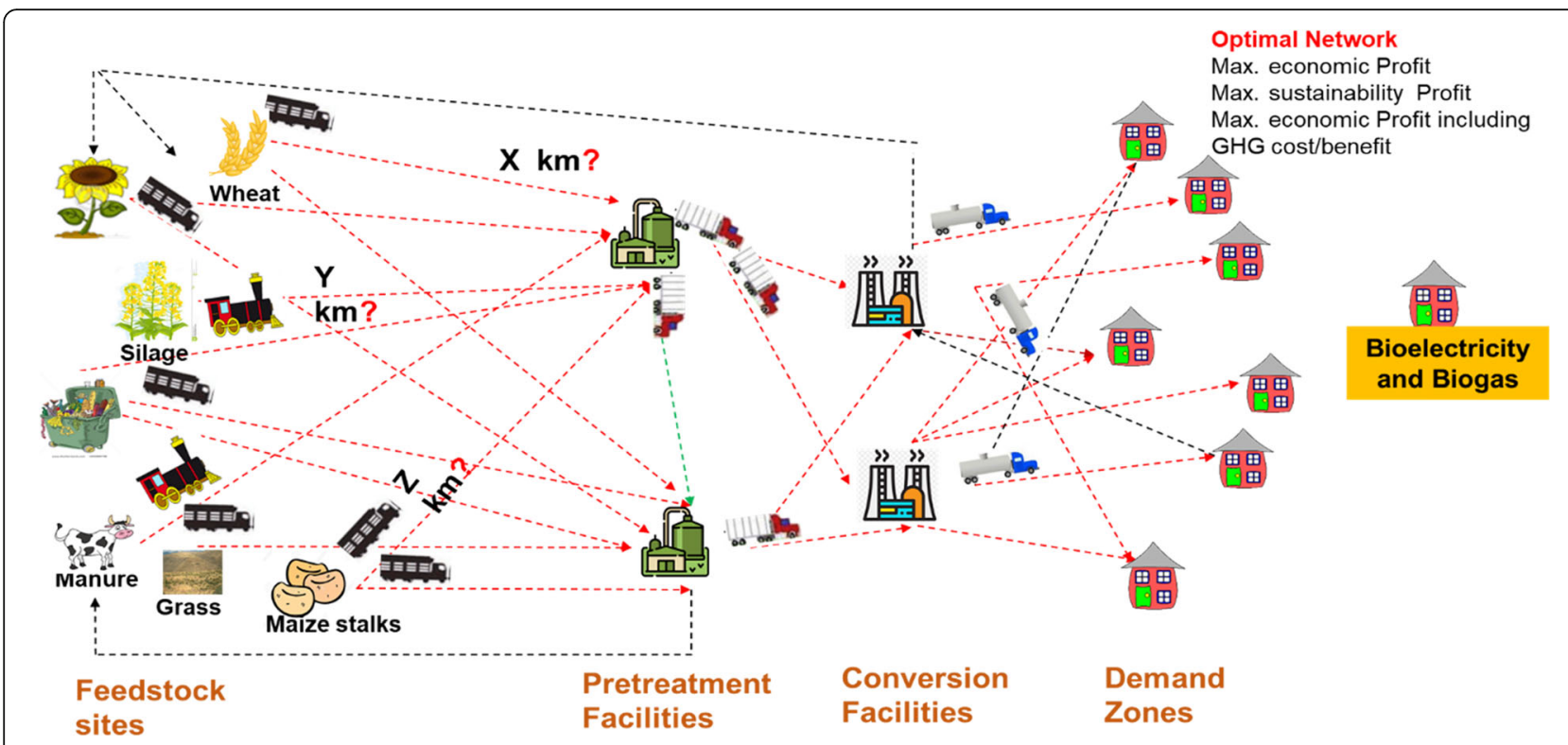

Fig. 1 Biogas supply network considering multiple objectives (modified from [28])

subsidies may be needed to make the biogas production plant profitable in a case where GHG emission unburdening is not considered;

- Shortening the length of the time period which will enable higher differences in electricity prices. Additionally, this scenario shows the relation between the investment cost of biogas storage, the volume of biogas stored and electricity production.

- Varying the capacity of the biogas plant capacity from $1 \mathrm{MW}$ to $5 \mathrm{MW}$ while observing its effects on economic profits.

It follows that the variables to be optimized are:

- quantity, geographical location and total acquisition cost of feedstocks and/or raw materials;

- cost incurred in the supply chain and types of transport modes selected;

- other supply network management costs (depreciation, maintenance, operating, storage...);

- primary and secondary conversion facilities location and capacities;

- the sustainability profits effect on the supply network;

- global warming (GHG emissions) effect on the supply network;

- impact of the solution on the profit maximization;

- trade-offs when choosing different objectives;

- subsidies required to obtain economic break-even point for biogas production.

The general model (MILP problem) discussed in Egieya et al. [28] is also applicable to this study which is slightly extended to include new economic, environmental and social sustainability objectives.

\section{Methodology}

This work follows the concept put forward by Egieya et al. [28] while considering the following additions and extensions:

- The model is formulated on an hourly basis (previously on monthly basis in Egieya et al. [28]), where the year is divided into monthly $(m p)$, daily $(d p)$ and hourly $(h p)$ time periods. Consequently, all the equations which were based on monthly periods, are now delineated to monthly, daily and hourly periods. To implement this, certain model reduction techniques are therefore introduced to reduce computational time.

- Instead of subsidized prices of electricity (fixed), hourly-based auction trading prices of electricity are considered based on 2017 prices, ranging from 42.93 to $199.00 € /$ MWh (between - 57.1 and 264.67 $\$ / M W h)$ [33]. The highest electricity price was in August, while the lowest price was in December 2017. The hourly-based electricity price variations are illustrated in Figs. 2 and 3 for the months of August and December 2017. All the data related to electricity prices (in $€ / M W h$ ) as obtained from BSP South Pool Energy Exchange [33] are presented in Additional file 1: Tables S1-S12). Furthermore, the average electricity prices (in $\$ / \mathrm{MWh}$ ) for each of the considered period based on model reduction techniques and implemented 


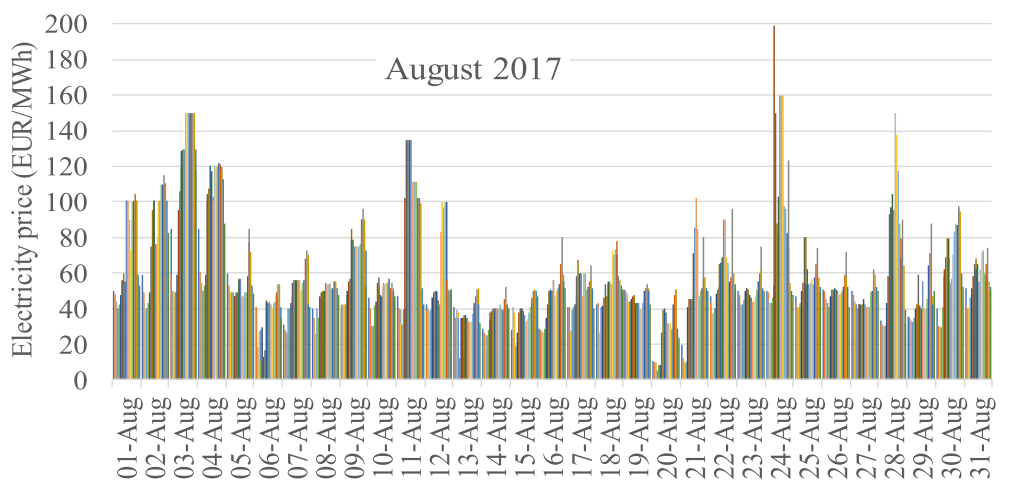

Fig. 2 Hourly-based electricity prices for August 2017 (data obtained from [33])

in the model are also given in the Additional file 1: Tables S13-S24).

- Biogas storage is incorporated to account for possible variations in electricity production, i.e. to enable storing biogas instead of electricity production at low electricity prices. However, in such situations, heat is also not produced, and thus a backup is required to generate heat from other sources.

- Instead of considering only one agricultural biogas production plant as the optimal plant and with the capacity of up to $999 \mathrm{~kW}$, a maximum of three biogas plants could be selected. Despite the variations in electricity production, biogas production should be constant with slight variations allowed. Thus two scenarios are performed based on the demand for methane, i) between $1.95 \cdot 10^{6}$ and $2.38 \cdot 10^{6} \mathrm{~m}^{3} / \mathrm{y}$ (average $0.9-1.1 \mathrm{MW}$ of electricity produced) and ii) between $9.76 \cdot 10^{6}$ and $11.93 \cdot 10^{6}$ $\mathrm{m}^{3} / \mathrm{y}$ (average 4.8-5.2 MW of electricity produced).

- Two additional objectives are considered besides an economic one in the form of maximizing sustainability profit [26] and the simultaneous maximization of profit with the costs and the benefits attributed to GHG burdening and unburdening. Hence, the model is upgraded to include environmental (GHG emissions) and sustainability (eco-cost and benefit and social cost and benefit) objectives.

\section{Description of biogas supply network}

The biogas supply network utilized (see Fig. 4) consists of four layers:

i) First layer (L1): harvesting and collection. This layer consists of a set $p b$ of biomass feedstocks (corn, wheat and triticale grains, straw, silage, and grass silage) and different manure types (cattle, pig and poultry manure, poultry bedding and poultry slurry). For the feedstocks, characteristics such as dry matter and methane contents and biogas yields [34] are considered in the study.

ii) Second layer (L2): primary processing technology which is anaerobic digestion. In L2, the primary conversion product $p i$ (a combination of biomass and waste feedstocks $p b$, recycled products poutpim and purchased products pbuy) is generated. These are later converted to intermediate products $p m$

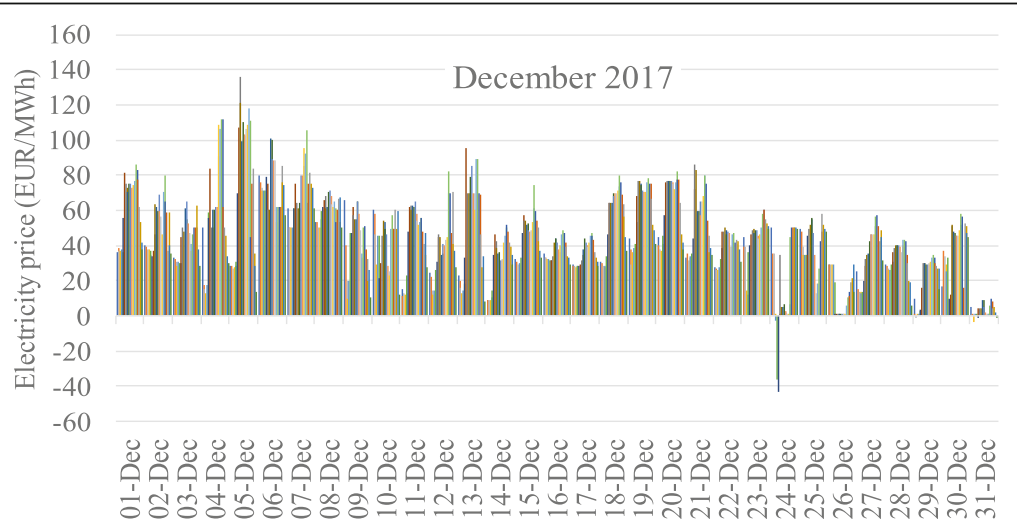

Fig. 3 Hourly-based electricity prices for December 2017 (data obtained from [33]) 


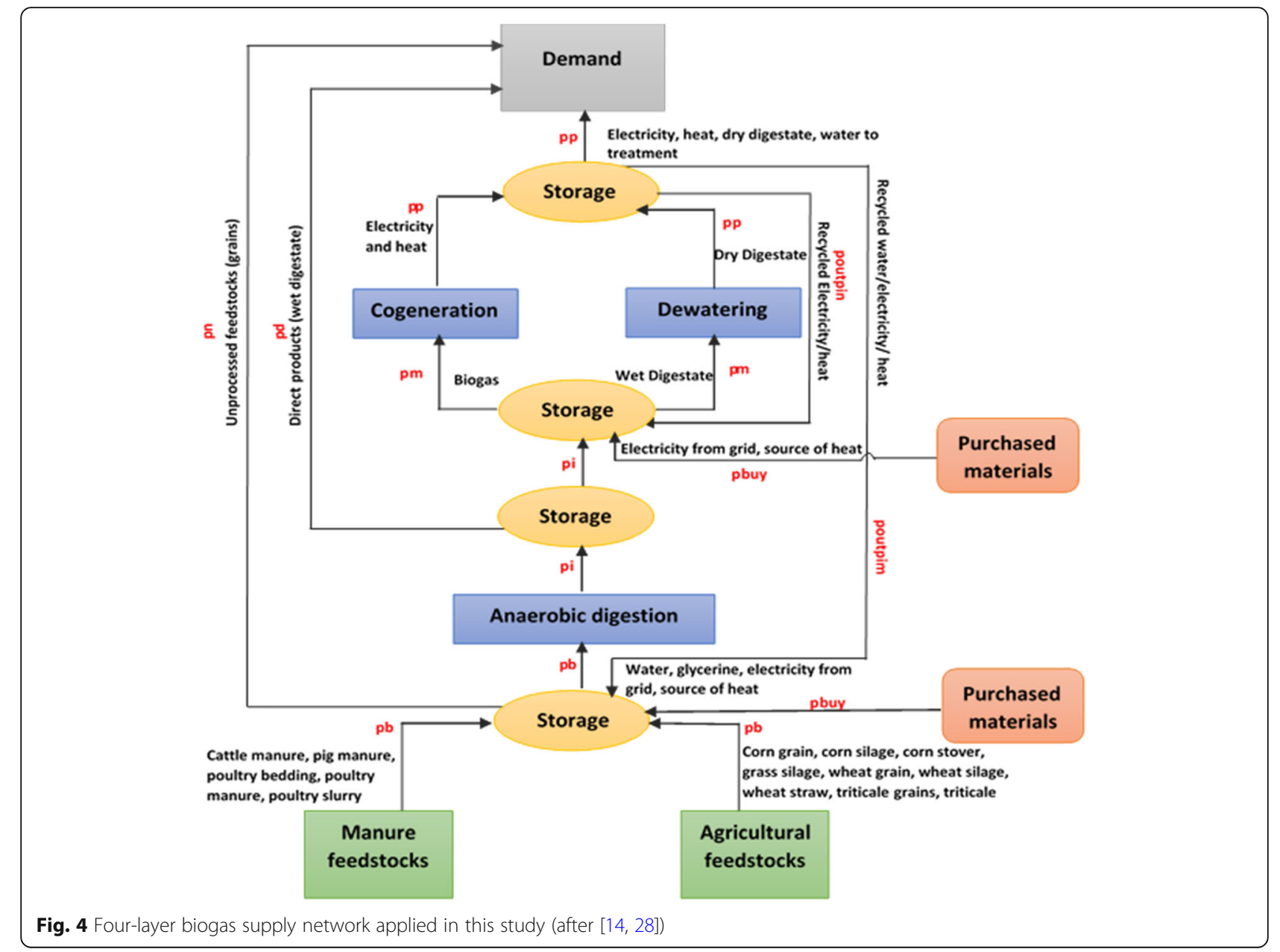

(biogas and wet digestate) or final products $p d$ using given conversion factors.

iii) Third layer (L3): secondary conversion technologies involve cogeneration (CHP) combining heat and power production and physical dewatering as in [28]. It should be noted that there are other possible conversion technologies, such as biogas upgrading to biomethane [35], ammonium sulfate recovery from digestate [36] and several other, however they have not been considered in this study. The products $p z$ (a sum of intermediate products pm, recycled product poutpin, and purchased products pbuy) are converted (using conversion factors) to the desired products $p p$ (electricity, heat and dry digestate).

iv) Fourth layer (L4): demand locations.

The model considers three optional distribution modes between the layers to convey feedstocks, intermediate and final products, in the form of road, pipeline transport, and transmission lines. Besides, the model allows heat and electricity generated from the $\mathrm{CHP}$ and water from the dewatering plants to be reused within the supply network. For sustainable supply of all materials within the supply network, four storage facilities are also modelled at the locations of biomass and waste collection centres and primary and secondary conversion facilities, where all feedstocks and products could be stored. Additionally, it is assumed that water, electricity, and heat are excluded from storage and that the purchased materials should not be stored. Note that from the previous work of Egieya et al. [28] biogas could additionally be stored.

Similarly, as in Egieya et al. [28], certain characteristics of biomass and waste feedstocks are considered, such as different dry matter contents, methane contents and biogas yields [34]. Also, other parameters as presented in Egieya et al. [28] are considered, except instead of guaranteed purchase prices which are fixed, auction trading prices which vary hourly are considered.

For more details on the biogas production supply network methodology, the reader is referred to the paper by Egieya et al. [28]. 


\section{Description of mathematical model}

The mathematical model includes material and energy balances, primary and secondary conversion constraints and cost correlations. However, as the model now considers hourly production, all the variables, and equations which were based on monthly periods, are now based on monthly, daily and hourly periods.

As the hourly-based model is computationally expensive, certain model reduction techniques have been implemented based on the work by Lam et al. [37] to reduce computational time. Hence, instead of $24 \mathrm{~h}$ a day, three "hourly periods" or shift periods (morning, afternoon and night) are considered and are thereby defined as $\mathrm{H} 1(7 \mathrm{am}-2 \mathrm{pm}), \mathrm{H} 2(3 \mathrm{pm}-10 \mathrm{pm})$ and $\mathrm{H} 3(11 \mathrm{pm}$ - $6 \mathrm{am}$ ). Furthermore, instead of 28-31 days a month, seven "daily periods" are applied based on the days of the week (Monday - Sunday) and are defined as D1: $\left\{d_{1}, d_{8}, d_{15}, d_{22}, d_{29}\right\}, \quad \mathrm{D} 2:\left\{d_{2}, d_{9}, d_{16}, d_{23}, d_{30}\right\}$, D3: $\left\{d_{3}\right.$, $\left.d_{10}, d_{17}, d_{24}, d_{31}\right\}$, D4: $\left\{d_{4}, d_{11}, d_{18}, d_{25}\right\}$, D5: $\left\{d_{5}, d_{12}, d_{19}\right.$, $\left.d_{26}\right\}$, D6: $\left\{d_{6}, d_{13}, d_{20}, d_{27}\right\}$ and D7: $\left\{d_{7}, d_{14}, d_{21}, d_{28}\right\}$, see also Egieya et al. [20]. This is due to different electricity consumption patterns of the weekdays and weekends. All 12 months of a calendar year are on the other hand fully considered in order to preserve the variability of the model as much as practicable. Merging of time periods is done by defining the sets MPOM, DPOD and $H P O H$ which convert the maximal number of time periods (mpo, dpo and $h p o$ ) to merged time periods ( $m p$, $d p$ and $h p)$.

All the prices except electricity prices are considered at merged hourly basis as shown in Eq. (1):

$$
\begin{gathered}
P_{p, m p, d p, h p}=\frac{\sum_{m p o \in M P} \hat{(m p o, m p) \in M P O M} P_{p, m p o}}{\sum_{\substack{m p o \in M P \\
(m p o, m p) \in M P O M}}^{\wedge}|m p o|}, \\
\forall p \in P \wedge p \notin\{\text { electricity }\}, m p \subseteq M P, d p \subseteq D P, h p \subseteq H P,(d p, m p) \in D P M
\end{gathered}
$$

where $\wedge$ stands for logical condition (dollar operator in GAMS [38]).

As electricity prices are provided on hourly basis, they are averaged in order to more properly account for their variations. Averaging electricity prices is illustrated in Eq. (2):

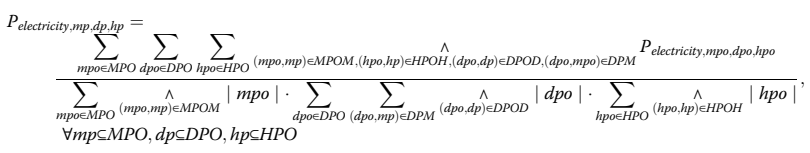

The hourly-based variations in the model have been introduced with the production rate of feedstocks $p b$ at the harvesting zone $i$, which is now defined based on merged hourly periods $h p$, merged daily periods $d p$ and monthly periods $m p\left(P R_{i, p b}, m p, d p, h p\right.$ in kt/period), see also Eq. (7) in Egieya et al. [28]:

$$
\begin{array}{rl}
\sum_{d p \subseteq D P} & \sum_{h p \subseteq H P}(d p, m p) \in D P M \\
=H Y_{i, p b, m p} & P R_{i, p b, m p, d p, h p} \\
\cdot & \cdot A_{i, p b, m p}, \quad \forall i \in I, p b \in P B, m p \in M P
\end{array}
$$

where $H Y_{i, p b, m p}$ is the yield of feedstocks $p b$ in month period $m p$ at harvesting zone $i$ (in $\mathrm{kt} /\left(\mathrm{km}^{2} \cdot\right.$ month)) and $A_{i, p b, m p}$ is the available area for growing biomass $p b$ at harvesting zone $i$ in month period $m p$ (in $\mathrm{km}^{2}$ ).

The equations for storages additionally consider "circular operations". The equation for storage at the inlet of primary conversion facilities is for example defined as shown in Eq. (4), see also Eq. (9) in Egieya et al. [28].

$$
\begin{aligned}
& A i n_{m, p i, m p, d p, h p}^{\mathrm{L} 2}=\underset{\left(m p_{k}\right)_{k \in K}, k=1 \wedge\left(d p_{k}\right)_{k \in K}, k=1 \wedge\left(h p_{k}\right)_{k \in K}, k=1}{\cup} A i n_{m, p i, m p--1, d p--1, h p--1}^{\mathrm{L} 2}+ \\
& \underset{\left(h p_{k}\right)_{k \in K}, k>1}{\cup} \operatorname{Ain}_{m, p i, m p, d p, h p-1}^{\mathrm{L} 2}+\underset{\left(d p_{k}\right)_{k \in K}, k>1 \wedge\left(h p_{k}\right)_{k \in K}, k=1}{\cup} \operatorname{Ain}_{m, p i, m p, d p-1, h p--1}^{\mathrm{L} 2}+ \\
& \left(m p_{k}\right)_{k \in K}, k>1 \wedge\left(d p_{k}\right)_{k \in K}, k=1 \wedge\left(h p_{k}\right)_{k \in K}, k=1 \\
& \sum_{i \in I}^{\left(m p_{k}\right)_{k \in K}, k>1 \wedge\left(d p_{k}\right)_{k \in K}, k=1 \wedge\left(h p_{k}\right)_{k \in K}, k=1} F_{i, m, p b, m p, d p, h p}^{\mathrm{L} 1, \mathrm{~L} 2, n e t}+\sum_{n \in N} \sum_{\text {poutpim } \subseteq P I} F_{n, m, \text { poutpim, mp }, d p, h p}^{\mathrm{L} 3, \mathrm{~L} 2, \text { net }}+ \\
& \sum_{p b u y \subseteq P I} F_{m, p b u y, m p, d p, h p^{-}}^{\mathrm{buy}, \mathrm{L} 2} \sum_{(p i, t) \in P I T \wedge t_{2} \in T} F_{m, p i, t, m p, d p, h p^{-}}^{\mathrm{L} 2, \mathrm{~T}} \sum_{j \in J} \sum_{p n \subseteq P I} F_{m, j, p n, m p, d p, h p}^{\mathrm{L} 1, \mathrm{~L} 4, \mathrm{net}}+ \\
& \left(A i n_{m, p i, m p, d p, h p}^{\mathrm{L} 2}+\underset{\left(m p_{k}\right)_{k \in K}, k=1 \wedge\left(d p_{k}\right)_{k \in K}, k=1 \wedge\left(h p_{k}\right)_{k \in K}, k=1}{\cup} \operatorname{Ain}_{m, p i, m p--1, d p--1, h p--1}^{\mathrm{L} 2}+\right. \\
& \underset{\left(h p_{k}\right)_{k \in K}, k>1}{\cup} \operatorname{Ain}_{m, p i, m p, d p, h p-1}^{\mathrm{L} 2}+\underset{\left(d p_{k}\right)_{k \in K}, k>1 \wedge\left(h p_{k}\right)_{k \in K}, k=1}{\cup} \operatorname{Ain}_{m, p i, m p, d p-1, h p--1}^{\mathrm{L} 2}+ \\
& \underset{\left(m p_{k}\right)_{k \in K}, k>1 \wedge\left(d p_{k}\right)_{k \in K}, k=1 \wedge\left(h p_{k}\right)_{k \in K}, k=1}{U} \operatorname{Ain}_{m, p i, m p-1, d p--1, h p--1}^{\mathrm{L} 2}+ \\
& \left.\underset{\left(m p_{k}\right)_{k \in K}, k>1 \wedge\left(d p_{k}\right)_{k \in K}, k=1 \wedge\left(h p_{k}\right)_{k \in K}, k=1}{U} \operatorname{Ain}_{m, p i, m p-1, d p--1, h p--1}^{\mathrm{L} 2}\right) / 2 \cdot \psi_{p i, m p, d p, h p} \\
& \forall m \in M, p i \in P I \wedge p i \notin N O S T O R, m p \in M P, d p \in D P, h p \in H P,(d p, m p) \in D P M
\end{aligned}
$$

In Eq. (4) $A i n_{m, p i, m p, d p, h p}^{\mathrm{L} 2}$ represents the storage quantity of material $p i$ in each monthly $m p$, daily $d p$ and hourly time period $h p$ at the location of primary conversion facility $m$, $A i n_{m, p i, m p--1, d p--1, h p--1}^{\mathrm{L} 2}$ refers to the quantity of material $p i$ in the storage tank at the beginning of January (first hour, first day and first month) which equals the quantity of material $p i$ in the storage tank at the last hour of December (last hour, last day, last month) of the previous year. Similarly, $A i n_{m, p i, m p, d p, h p-1}^{\mathrm{L} 2}$ refers to quantity of material $p i$ in the storage tank for each month and day where the hour should not be the first hour of the day, $A i n_{m, p i, m p, d p-1, h p--1}^{\mathrm{L} 2}$ refers to the quantity of material $p i$ in the storage tank for each first hour of the day and if the day is not the first day of the month and $A i n_{m, p i, m p-1, d p--1, h p--1}^{\mathrm{L} 2}$ refers to quantity of material $p i$ in the storage tank for each first hour in a day and for each first day in a month of any given month except January (first month).

Additional terms in Eq. (4) are: $F_{i, m, p b, m p, d p, h p}^{\mathrm{L} 1 \mathrm{~L} 2, n e p r e s e n t s}$ the net quantity of biomass and waste feedstocks $p b$ shipped to the primary conversion location $m$ from the harvesting location $i$ in each considered time period ( $m p, d p, h p)$, $F_{n, m, \text { poutpim,mp,dp,hp }}^{\mathrm{L}, \mathrm{L} 2, \text { is }}$ the net flow of "recycled" material in 
the supply network poutpim between the secondary $n$ and primary conversion location $m$, also for each considered time period. Such products are electricity, heat and water, as shown in Fig. 4. $F_{m, p b u y, m p, d p, h p}^{\mathrm{buy}, \mathrm{L} 2}$ stands for the quantity of purchased resources pbuy to be used at L2 (primary conversion) on the location of $m$ in each of the considered time period. $F_{m, p i, t, m p, d p, h p}^{\mathrm{L} 2, \mathrm{~T}}$ is the flow of intermediate product $p i \in$ (pb, poutpim, pbuy) from storage to technology $t_{2} \in T$ at primary conversion location $m$ in each time period and $F_{m, j, p n, m p, d p, h p}^{\mathrm{L} 1, \mathrm{~L} 4}$ quantifies the flow of unprocessed feedstocks $p n \subseteq P I$ to the demand location $j$. The last term of Eq. (4) represents the losses of stored intermediate materials pi during the storage. Similarly as in Egieya et al. [28], it is assumed that the amount of stored intermediate products $(p i \in P I \wedge p i \notin N O S T O R)$ available in any considered time period $m p, d p, h p$ is the average of two consecutive time periods. Parameter $\psi_{p i, m p, d p, h p}$ represents the deterioration rate in storage which is defined on monthly basis $\psi_{p i, m p}$, and is then divided by the length of the daily and hourly period (cardinality of sets $D P$ and $H P$ ), as shown in Eq. (5):

$\psi_{p i, m p, d p, h p}=\frac{\psi_{p i, m p}}{|d p \| h p|}, \forall p \in P, m p \in M P, d p \in D P, h p \in H P,(d p, m p) \in D P M$

As it was stated above, all the potential biogas plants could be selected. Since only slight variations in capacity of anaerobic digesters are allowed, two scenarios are performed based on the demand for methane, i) between $1.95 \cdot 10^{6}$ and $2.38 \cdot 10^{6} \mathrm{~m}^{3} / \mathrm{y}$ (average $0.9-1.1 \mathrm{MW}$ of electricity produced) and ii) between $9.76 \cdot 10^{6}$ and $11.93 \cdot 10^{6}$ $\mathrm{m}^{3} / \mathrm{y}$ (average $4.8-5.2 \mathrm{MW}$ of electricity produced). The capacities of methane between their upper and lower bounds are shown in Eq. (6) for lower bound and in Eq. (7) for upper bound.

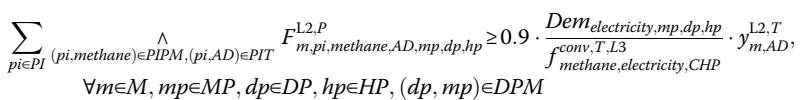

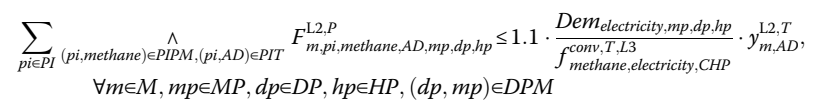

In Eq. (6) and Eq. (7) $F_{m, p i, m e t h a n e, A D, m p, d p, h p}^{\mathrm{L} 2, P}$ represents the flowrate of methane produced from material $p i$ using anaerobic digestion $\mathrm{AD}$ technology at $\mathrm{L} 2$ within time periods $m p, d p, h p$. Dem electricity, $m p, d p, h p$ stands for the demand for electricity in each considered time period (see

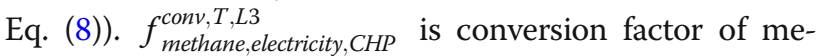
thane to electricity using technology CHP, and the binary variable $y_{m, A D}^{\mathrm{L} 2, T}$ represents the selection of technology $\mathrm{AD}$ at location $m$. If the binary variable equals $1, A D$ is selected at $m^{\text {th }}$ location while the $\mathrm{AD}$ is not selected at that location when the binary variable equals to 0 .

$$
\begin{gathered}
\text { Dem }_{\text {electricity,mp,dp }, h p}=\text { cap } \cdot f_{\text {time }} \cdot \frac{|m p o|}{|m p|} \cdot \frac{|d p o|}{|d p|} \cdot \frac{|h p o|}{|h p|}, \\
\forall m p \in M P, d p \in D P, h p \in H P,(d p, m p) \in D P M
\end{gathered}
$$

where cap is capacity of electricity production ( 1 or 5 $\mathrm{MW}$ ) and $f_{\text {time }}$ is the fraction of time when biogas production is operating and is defined as the number of operating hours in a year divided by the total number of hours in a calendar year. In this study, value of 0.935 $(8192 \mathrm{~h} / \mathrm{y})$ is assumed for $f_{\text {time }}$. The part $\frac{|m p o|}{|m p|} \cdot \frac{|d p o|}{|d p|} \cdot \frac{|h p o|}{|h p|}$ relate to the number of all periods divided by the total number of considered periods.

Moreover, various new equations, data and variables have been included in the model to account for the two additional objectives included in this study compared to the work of Egieya et al. [28]. These equations and variables related to the additional objectives are hereby presented in the next section and the data assumed are presented in Additional file 1. The data related to GHG emissions are shown in Additional file 1: Tables S25 - S27 and the data related to sustainability profit maximization are given in Additional file 1: Tables S28 - S31.

\section{Objectives in the study}

The goal is to synthesize an optimal biogas supply network under different objective functions: (i) economic objective defined with maximizing economic profit (similar to Egieya et al. [20, 28], while excluding the tax on the profit accrued); (ii) economic and environmental objectives by maximizing economic profit while including costs and benefits due to GHG emissions (price for GHG emissions), and iii) economic, environmental and social objectives by maximizing sustainability profit [26] which includes all three sustainability objectives, economic, environmental and social (similar as in Bogataj et al. [39]). Further, four additional scenarios are performed to improve the profitability of the biogas supply network: i) price for GHG emissions is increased from the price of carbon allowances in the European Union Emissions Trading System (EU ETS) [40] up to the value of eco-costs / benefits of global warming [32], ii) the auction trading prices are increased by multiplying them with various factors, as explained above iii) the length of time period is decreased and the relation is explored between the price of biogas storage and capacity of biogas storage and electricity production and (iv) increasing the biogas plant capacity from $1 \mathrm{MW}$ to $5 \mathrm{MW}$ and observing its effects on economic profit. 


\section{Economic objective}

The economic objective is defined with maximizing economic profit $\left(P^{\text {Economic }}\right)$ from the generation of electricity, heat and digestate within the biogas supply chain network:

$$
P^{\text {Economic }}=R^{\text {Total }}-C^{\text {Total }}
$$

where $R^{\text {Total }}$ is total revenue accrued $(\$ / \mathrm{y})$ and $C^{\text {Total }}$ is total cost incurred in the supply chain $(\$ / y)$.

The total revenue $\left(R^{\text {Total }}\right)$ is calculated as shown in Eq. (10):

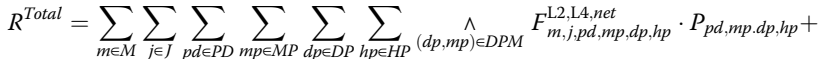

$$
\begin{aligned}
& \sum_{n \in N} \sum_{j \in J} \sum_{p p \in P P} \sum_{m p \in M P} \sum_{d p \in D P} \sum_{h p \in H P} \underset{(d p, m p) \in D P M}{\wedge} F_{n, j, p p, m p, d p, h p}^{\mathrm{L}, \mathrm{L} 4, n e t} \cdot P_{p p, m p, d p, h p}+
\end{aligned}
$$

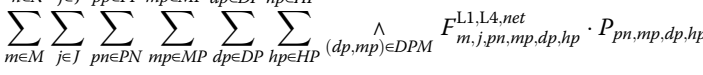

where $F_{m, j, p d, m p, d p, h p}^{\mathrm{L} 2, \mathrm{~L} 4, n e t}$ represents the net flowrate of direct product $p d$ (wet digestate) produced from anaerobic digestion at site $m$ and sold as a fertilizer in site $j$ to farmers at each considered time period, $F_{n, j, p p, m p, d p, h p}^{\mathrm{L}, \mathrm{L} \mathrm{L}, n e t}$ stands for the net flow of produced products $p p$ (electricity, heat and dewatered digestate) from the plant $n$ to demand $j . F_{m, j, p n, m p, d p, h p}^{\mathrm{L} 1 \mathrm{~L} 4, n e t}$ represents materials that do not undergo any treatment $(p n)$ shipped directly to the demand zone in site j. $P_{p d, m p . d p, h p}, P_{p p, m p, d p, h p}$ and $P_{p n}$, $m p, d p, h p$ are prices of direct products $(p d)$, produced products $(p p)$ and products that do not undergo treatment $(p n)$.

Total costs accrued $\left(C^{\text {Total }}\right)$ in the biogas supply chain network are a sum of costs for feedstocks, purchase of additional materials needed in L2 and L3, shipment ( $T$ $\left.C_{p}^{\text {Total }}\right)$, storage $\left(S C_{p}\right)$, labour $(L C)$, depreciation $(D C C)$, maintenance $(M C)$, and miscellaneous cost $(M S C)$ as displayed in Eq. (11):

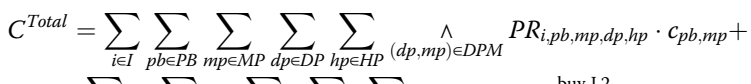

$$
\begin{aligned}
& \sum_{m \in M} \sum_{p b u y \in P B U Y} \sum_{m p \in M P} \sum_{d p \in D P} \sum_{h p \in H P} \wedge_{(d p, m p) \in D P M} F_{m, p b u y, m p, d p, h p}^{\mathrm{buy}, \mathrm{L} 2} \cdot c_{p b u y, m p}+ \\
& \sum_{n \in N} \sum_{p b u y \in P B U Y} \sum_{m p \in M P} \sum_{d p \in D P} \sum_{h p \in H P} \stackrel{\wedge}{\wedge} \wedge_{p, m p) \in D P M} F_{n, p b u y, m p, d p, h p}^{\mathrm{buy}, \mathrm{L} 3} \cdot c_{p b u y, m p}+ \\
& \sum_{p \in P} T C_{p}^{\text {Total }}+\sum_{p \in P} S C_{p}+L C+D C C+M C+M S C
\end{aligned}
$$

where, $c_{p b, m p}$ and $c_{p b u y, m p}$ are cost for feedstocks acquired $(p b)$ and purchased materials (pbuy). $P R_{i, p}, m p$, $d p, h p$ is total quantity of feedstocks harvested at site $i$ and shipped to storage at primary conversion location, while $F_{m, p b u y, m p, d p, h p}^{\mathrm{buy}, \mathrm{L} 2}$ and $F_{n, p b u y, m p, d p, h p}^{\mathrm{buy}, \mathrm{L} 3}$ are quantities of additional raw materials purchased in L2 and L3 within a given monthly, daily and hourly period.

\section{Economic and environmental objectives (economic ${ }^{+G H G}$ profit)}

The second objective includes economic objective and price for GHG emissions. The economic objective and equations describing it in detail are shown above (Eqs. (9)-(11)). The environmental objective is defined as a maximization of GHG unburdening and it is based and extended from the work of Bogataj et al. [39]. Avoided and released GHG emissions (unburdening and burdening) are multiplied by the price of GHG emissions (also called carbon price [41]) and included in the economic objective. Both burdening and unburdening are considered, whereby burdening is related to the negative impacts on the environment due to resource use, production and use of products, while unburdening is due to the direct utilization of harmful (waste) materials and due to substitution of environmentally more harmful products with less harmful ones [42].

The environmental objective follows the same principle of evaluation as the eco-profit calculation [30]. First, avoided and released GHG emissions are calculated with units based on $\mathrm{CO}_{2}$ equivalent emitted per $\mathrm{t}$ of raw material or product except for electri-

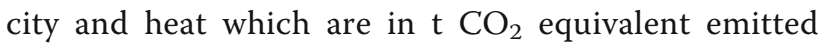
per MWh. The Life Cycle Assessment (LCA) principle is applied to the biogas supply network from the harvesting and collection zones to the demand zones. GHG emissions include those emissions that originate from the whole life cycle of product, from extraction of raw materials, through pre-processing and processing to disposal of harmful products, including emissions due to transportation and distribution within the supply network (similarly as in [30]).

Hence, the amounts of GHG emitted or preserved (see Eq. (12)) is a measure of the difference between GHG unburdening $\left(G H G^{U B}\right)$ as shown in Eq. (13) and GHG burdening $\left(G H G^{B}\right)$ in the supply network, presented by Eq. (14).

$$
\begin{aligned}
G H G & =G H G^{U B}-G H G^{B} \\
G H G_{p}^{U B} & =\sum_{m \in M} \sum_{t \in T} \sum_{m p \in M P} \sum_{d p \in D P} \sum_{h p \in H P} F_{m, p, t, m p, d p, h p}^{\mathrm{L} 1 \mathrm{~L}, 2, n e t} \cdot c_{p}^{G H G, U B}+ \\
& \sum_{m \in M} \sum_{j \in J} \sum_{m p \in M P} \sum_{d p \in D P} \sum_{h p \in H P} F_{m, j, p, n, m p, d p, h p}^{\mathrm{L} 2 \mathrm{~L}, n e t} \cdot c_{p}^{G H G, U B} \cdot f_{p}^{S}+ \\
& \sum_{n \in N} \sum_{j \in J} \sum_{m p \in M P} \sum_{d p \in D P} \sum_{h p \in H P}^{L_{n, j, p, m p, d p, h p}} \cdot c_{p}^{G H G, U B} \cdot f_{p}^{S}, \quad \forall p \in\{P B, P D, P P\}
\end{aligned}
$$

where, $c_{p}^{G H G, U B}$ is the GHG emission coefficient related to unburdening or avoided GHG emissions (see Additional file 1: Table S25) for material $p$ and $f_{p}^{S}$ is substitution factor defined as the amount of produced product divided by the amount of substituted product [30]. GHG emission coefficients have been obtained from the 
website of Delft University of Technology, The Model of the Eco-costs / Value Ratio (EVR) [32] and checked with OpenLCA software [43] using ecoinvent 3.1 database [44] and the ecoinvent 3.1 Life Cycle Impact Assessment (LCIA) method [45] IPCC 2007.

The following substitution factors are assumed in the study: 0.9 for electricity, 0.04 for dry digestate and 0.029 for wet digestate [46].

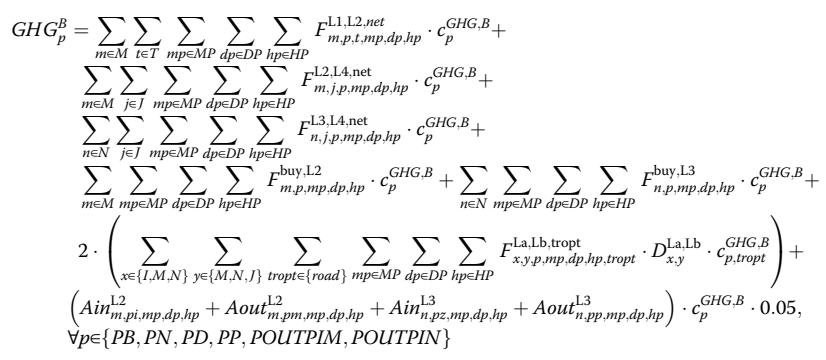

where $c_{p}^{G H G, B}$ refers to the GHG emission coefficient of material $p$ related to the released GHG emissions (burdening) (see Additional file 1: Table S26), $c_{p, \text { tropt }}^{G H G}$ is GHG emission coefficient related to transport (see Additional file 1: Table S27). In addition, it is worth stating that the last section of the Eq. (14) illustrates the GHG emissions occurring during storage of material $p$ over the considered time periods. Hence, in the storage, it is assumed that the burdening equals $5 \%$ of the burden of product stored.

Additional terms in Eq. (14) are: $F_{x, y, p, m p, d p, h p, \text { tropt }}^{\mathrm{La}, \mathrm{Lb}, \text { tropt }}$ shows the quantity of materials $p$ transported from the location $x$ in layer La to location $y$ in layer Lb with transportation mode tropt at the considered time period $m p, d p, h p, D_{x, y}^{\mathrm{La}, \mathrm{Lb}}$ is the distance between object $x$ in layer $\mathrm{La}$ and object $y$ in layer $\mathrm{Lb}$, and $A i n_{m, p i, m p, d p, h p}^{\mathrm{L} 2}$, Aout $t_{m, p m, m p, d p, h p}^{\mathrm{L} 2}, \quad \operatorname{Ain}_{n, p z, m p, d p, h p}^{\mathrm{L} 3}$ and Aout ${ }_{n, p p, m p, d p, h p}^{\mathrm{L} 3}$ stand for the quantity of $p i$ stored in the inlet of L2, the quantity of pm stored in the outlet of L2, the quantity of $p z$ stored in the inlet of L3 and for the quantity of $p p$ stored in the outlet of L3 in the assessed time periods.

It should be noted that for simplicity of this study, the emissions given off during constructing the biogas production plants and pipelines are omitted and as such, the equipment are assumed to be used over the entire lifetime of the plant. This assumption therefore suggests relatively small contribution of GHG emissions during construction over the plant's lifetime.

The objective which considers economic and environmental parts is defined as maximizing the economic profit while including the multiplication of the released and avoided GHG emissions with the prices of GHG emissions, $P^{\text {Economic }^{+G H G}}$ :

$$
P^{E \text { conomic }}{ }^{+G H G}=P^{E \text { conomic }}+G H G \cdot p^{G H G}
$$

where $p^{G H G}$ stands for the prices of GHG emissions.

\section{Economic, environmental and social objectives (sustainability profit)}

The third objective considers economic, environmental and social parts which implements the concept of Sustainability profit $\left(P^{\text {Sustainability }}\right)$, first proposed in Zore et al. [26]. $P^{\text {Sustainability }}$ combines economic, environmental and social indicators into monetary values $(\$ / y)$.

$P^{\text {Sustainability }}$ is stipulated mathematically (see Eq. (16)) as the sum of Economic profit ( $P^{\text {Economic }}$, see Eq. (9)), Eco-profit $\left(P^{E c o}\right.$, see Eq. (17)) and Social Profit $\left(P^{\text {Social }}\right.$, see Eq. (20)):

$$
P^{\text {Sustainability }}=P^{E c o n o m i c}+P^{E c o}+P^{\text {Social }}
$$

The eco-profit $\left(P^{E c o}\right)$ [30] derives from the difference between the sum of all the eco-benefits $(E B)$ and the eco-costs $(E C)$ within the biogas supply network:

$$
P^{E c o}=E B-E C
$$

Eco-benefit $(E B)$ (see Eq. (18)) is described in monetary terms $(\$ / y)$ as the sum of all positive impacts of activities/materials which unburden the environment while the eco-cost $(E C)$ (see Eq. (19)) shows the sum of all negative impacts of activities/materials which burden the environment [30].

$$
\begin{aligned}
& E B_{p}=\sum_{m \in M} \sum_{t \in T} \sum_{m p \in M P} \sum_{d p \in D P} \sum_{h p \in H P} F_{m, p, t, m p, d p, t p}^{\mathrm{L1} 1, \mathrm{~L}, \text {, } e t} \cdot c_{p}^{E B}+ \\
& \sum_{m \in M} \sum_{j \in J} \sum_{m p \in M P} \sum_{d p \in D P} \sum_{h p \in H P} F_{m, j, j, m p, d p, t p}^{\mathrm{L}, 2, \mathrm{LA}, \text { net }} \cdot c_{p}^{E B} \cdot f_{p}^{S}+
\end{aligned}
$$

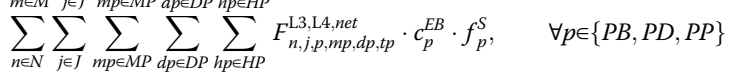

where $c_{p}^{E B}$ is the eco-benefit coefficient (see Additional file 1: Table S28) of material or energy $p(\$ / \mathrm{kg}, \$ / \mathrm{kWh})$. It is worth stating that Eq. (18) is formulated in a similar way as Eq. (13) but considers eco-benefit coefficients instead of GHG emission coefficients related to avoided GHG emissions. The same substitution factors are assumed as previously mentioned in the case of avoided GHG emissions due to substitution of products.

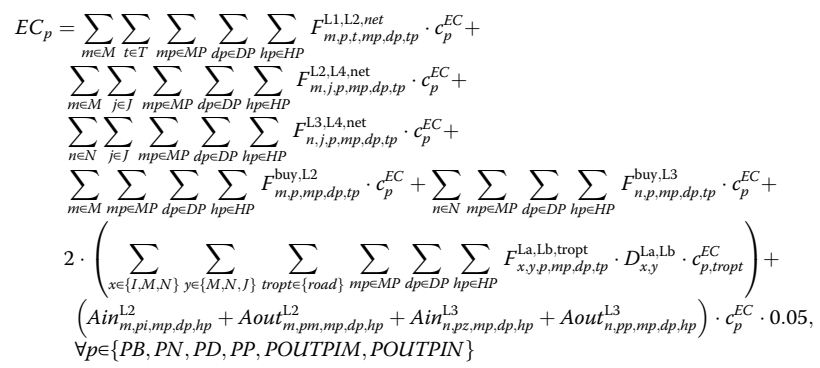


whereby $c_{p}^{E C}$ is the eco-cost coefficient for $p(\$ / \mathrm{kg})$ (see Additional file 1: Table S29) and $c_{p, t r o p t}^{E C}$ is eco-cost coefficient related to transport of material or energy $p$ $(\$ /(\mathrm{kg} \cdot \mathrm{km}), \$ /(\mathrm{kWh} \cdot \mathrm{km})$ ) (see Additional file 1: Table S30). More details on calculation of eco-profit could be found in Čuček et al. [30].

Eco-cost and eco-benefit coefficients have also been obtained from the website <ecocostvalue.com> [32] and checked with OpenLCA software [43], similarly as for GHG emission coefficients. Eco-costs express the amount of environmental burden a product causes based on prevention of that burden which tends to reduce the environmental pollution and materials depletion to a level which is in line with the Earth's carrying capacity [47]. Eco-costs consider environmental burden of global warming, acidification, eutrophication, summer smog, fine dust, eco-toxicity, and the use of metals, rare earth, fossil fuels, water and land [32]. Eco-benefits on the other hand represent the avoided cost due to avoided pollution [48] and thus more sustainable solutions are obtained as it is current practice, i.e. the solutions which represent the progress toward sustainable development [48].

The concept of Social Profit $\left(P^{\text {Social }}\right)$ first propounded in Zore et al. [26] is defined as the summation of paid Social Security (SS) contributions and the benefits related to creation of new jobs $\left(B^{\text {Jobs }}\right)$ subtracting the social cost $\left(c^{\text {Social }}\right)$ (see Eq. (20)). The Social Security (SS) contributions paid is a difference between average gross $\left(S_{t, m p}^{\text {Gross }}\right)$ and net salaries $\left(S_{t, m p}^{N e t}\right)$ in a given production sector per month using a given technology $t$ multiplied by the number of new jobs $\left(N_{t, m p}^{J o b s}\right)$ created. In addition, the benefits of the new jobs created $\left(B^{\text {Jobs }}\right)$ are the product of the average state/country social transfer for unemployed people $\left(c_{m p}^{s, U N E}\right)$ and $N_{t, m p}^{\text {Jobs }}$. Social costs $\left(c^{\text {Social }}\right)$ are described as the level of social support made by the state/country and organization to the employee(s), and in this respect is the product of number of new jobs created $\left(N_{t, m p}^{J o b s}\right)$ and sum of average state/country social transfer $\left(c_{m p}^{s, \text { Country }}\right)$ and organization social charge $\left(c_{m p}^{s, \text { Organisation }}\right)$ per employee. Additionally, the social costs within an organization refer to activities set aside to improve the social status of employees and the community as an extension. Such activities may include team building exercises, paid vacation, free accommodation within the organization's premises and others [26]. State/country social assistance on the other hand refers to such activities as improved health insurance, child allowance, scholarships and others. Hence, the general relation for the social profit is as given in Eq. (20):

$$
\begin{aligned}
& P^{\text {Social }}=S S+B^{\text {Iobs }}-C^{\text {Social }}= \\
& \sum_{m p \in M P} \sum_{t \in T} N_{t, m p}^{\text {Jobs }} \cdot\left[\left(S_{t, m p}^{\text {Gross }}-S_{t, m p}^{\text {Net }}\right)+c_{m p}^{s, \text { UNE }}-\left(c_{m p}^{\text {s.Country }}+c_{m p}^{s, \text { Organisation }}\right)\right]
\end{aligned}
$$

The number of new jobs created is given by Eq. (21) where, $L C$ is labour cost.

$$
N_{t, m p}^{J o b s}=\frac{L C}{|m p| \cdot S_{t, m p}^{G r o s s}}, \quad \forall t_{2} \in T, m p \in M P
$$

The parameters used to calculate social profit are taken from Zore et al. $[26,48]$ and are shown in Additional file 1: Table S31. For better understanding of mathematical model, a nomenclature of the notation used in Eqs. (1)-(21) can be found in Part B in Additional file 1 .

\section{Case study}

The model is implemented in a hypothetical case study considering three zones and three potential biogas supply networks in Slovenia (see Fig. 5), as in Egieya et al. $[20,28]$. Three locations each are put forward for the harvesting and collection sites, primary conversion, secondary conversion and demand, and the supply networks characteristics are as shown in Fig. 4. The same parameters as in Egieya et al. [28] are considered whereby the total area for each harvesting site is 250 $\mathrm{km}^{2}$, while $50 \%$ (Sites I and II) and 37\% (Site III) of the total area is available for growing crops. It is assumed that the primary conversion facilities include anaerobic digesters and the secondary conversion facilities include $\mathrm{CHP}$ and belt press dewatering. For more details regarding the case study and the assumptions, the reader is referred to Egieya et al. [28].

Moreover, differently to Egieya et al. [28], a maximum of three biogas plants (at Sites I-III) could now be selected, and two biogas plant capacities are considered (of about $1 \pm 0.1 \mathrm{MW}$ and $5 \pm 0.2 \mathrm{MW}$ average capacity of electricity production). Furthermore, instead of using subsidized prices of electricity, hourlybased auction trading prices (in $€ / \mathrm{MWh}$ ) of electricity are utilized based on the data retrieved from BSP South Pool Energy Exchange [33] (see Additional file 1: Tables S1-S12). Due to computational expenses in solving the models for each hour in a year, the days in each month are merged into days of the week (Monday, Tuesday, ..., Sunday) and the hours in each day are merged into 3 periods (morning, 7 am -2 $\mathrm{pm}$, afternoon, $3-10 \mathrm{pm}$, and night, $11 \mathrm{pm}-6 \mathrm{am}$ ) as discussed previously. The stipulated electricity prices $(\$ / \mathrm{kWh})$, in each period of a year, are presented in Additional file 1: Tables S13 - S24 where the conversion rate of $1.33 \$ / €$ is used (based on the works by Egieya et al. [17, 20, 28]. 


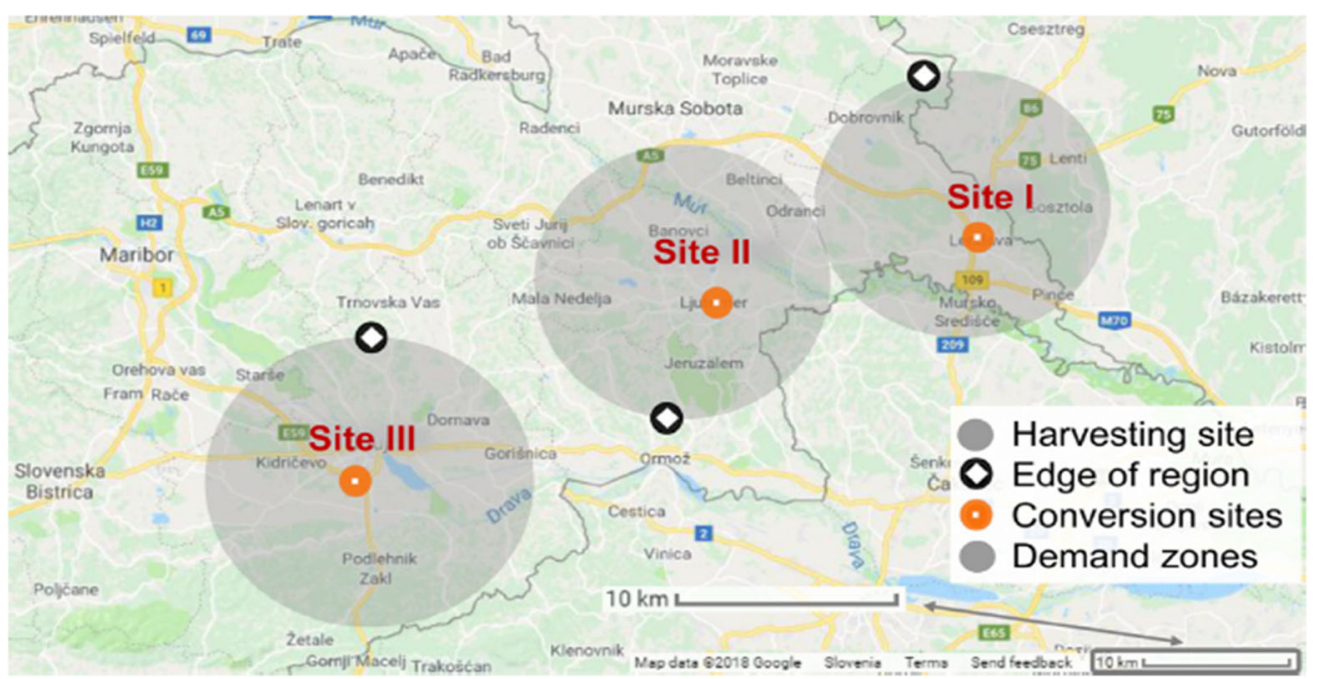

Fig. 5 Region in case study (after [28])

The optimizations were performed for two capacities of methane production and three different objectives (maximizing economic, economic ${ }^{+\mathrm{GHG}}$ and sustainability profits) while considering hourly, daily and monthly time periods. To determine the Economic ${ }^{+G H G}$ profit (see Eq. (15)), three new equations (see Eq. (12) - Eq. (14)) and the data as shown in Additional file 1: Tables S25 - S27 have been incorporated in the model. Concerning optimizing the Sustainability profit (see Eq. (16)) of the biogas supply network, five new equations (see Eq. (17) - Eq. (21) and the data presented in Additional file 1: Tables S28 - S31 has been used in the model.

Since the prices of electricity vary hourly while showing significant differences in prices, additional biogas storage is thereby introduced as opposed to the work of Egieya et al. [28] which excluded the use of biogas storage. The biogas storage facility suggests an increase in the storage of biogas during periods of low electricity prices while enhancing more electricity production at periods whereby the electricity prices are higher. The capital cost of the biogas storage is thus included, and its relationship with capacity is shown in Additional file 1: Figure S1.

However, like in Egieya et al. [28], agricultural residues could be used as potential feedstocks for biogas production while all the parameters related to grains (except the agricultural area) are now set to zero.

The upgraded models, also called BIOSOM models [28] containing 12 monthly, 7 daily and 3 hourly time periods comprise 327,042 single equations, 516,641 continuous variables, and 684 binary variables. The models formulated as MILP are solved using GAMS modelling environment and GUROBI solver with 0\% optimality gap on Intel $^{\circ} \mathrm{Core}^{\mathrm{Tm}}$ i7-8750 $\mathrm{H}$ CPU at $2.20 \mathrm{GHz}$ processor with $8 \mathrm{~GB}$ installed RAM. The average time for completion of each model is about $31 \mathrm{~min}$ within 532,726 iterations.

\section{Maximization of economic, economic ${ }^{+\mathrm{GHG}}$ and sustainability profits}

Firstly, the models are optimized on the different objectives, maximization of economic, economic ${ }^{+\mathrm{GHG}}$ and sustainability profits. As stated earlier, two capacity levels with specified demand for methane are considered: i) production of methane between $1.95 \times 10^{6}$ and $2.38 \times 10^{6} \mathrm{~m}^{3} / \mathrm{y}$ (average 0.9-1.1 MW of electricity produced), and ii) production of methane between $9.76 \times 10^{6}$ and $11.93 \times 10^{6} \mathrm{~m}^{3} / \mathrm{y}$ (average 4.8-5.2 MW of electricity produced). Table 1 shows the main results from the smaller capacity level and Table 2 shows results from the larger capacity level.

Considering the auction trading prices (averaged for 3 periods a day for all days in the week of each month in a year), economic losses are accrued in the objective scenarios as shown in Table 1. Furthermore, maximizing sustainability profit presents eco-profit values $(2,802,824$ $\$ / y)$ about 8.7 times more than that accrued when the economic $^{+ \text {GHG }}$ profit is maximized $(321,269 \$ / y)$ but an eco-profit loss is incurred when the economic profit is maximized. Moreover, the economic ${ }^{+\mathrm{GHG}}$ profit is negative in all scenarios while the social profit obtained during the maximization of sustainability $(230,344 \$ / t)$ is 3 times the social profit value obtained in other scenarios $(77,456 \$ / y)$ mainly due to three biogas plants and three times the number of employees required.

Alternatively, the total feedstock used to meet the sustainable production of electricity when sustainability profit is maximized $(85,200.3 \mathrm{t} / \mathrm{y})$ is about four times the feedstocks used when economic and economic ${ }^{+\mathrm{GHG}}$ profit is each maximized $(21,948.6 \mathrm{t} / \mathrm{y})$. It is worth stating that 
Table 1 Main results when maximizing different profits for biogas supply network with smaller capacity $(1 \pm 0.1 \mathrm{MW}$ in average electricity production)

\begin{tabular}{|c|c|c|c|}
\hline & Max PEconomic & Max $P^{E c o n o m i c}{ }^{+G H G}$ & Max $P^{\text {Sustainability b }}$ \\
\hline \multicolumn{4}{|l|}{ Feedstock (t/y) } \\
\hline Corn grain & 7488 & 7488 & 11,820 \\
\hline Corn silage & / & / & 14,354 \\
\hline Corn stover & 5105 & 5105 & 8059 \\
\hline Poultry bedding & 9355 & 9355 & / \\
\hline Poultry manure & 2236 & 2236 & 25,505 \\
\hline Poultry slurry & / & / & 25,463 \\
\hline Total feedstock & 21,949 & 21,949 & 85,200 \\
\hline \multicolumn{4}{|l|}{ Products } \\
\hline Electricity (MWh/y) & 8386 & 8368 & 23,968 \\
\hline Heat (MWh/y) & 5955 & 5955 & 17,378 \\
\hline Digestate ( $23 \%$ dry solids, t/y) & 13,353 & 13,399 & 48,749 \\
\hline Corn grain (direct product) & 7239 & 7239 & 11,424 \\
\hline \multicolumn{4}{|l|}{ Water (t/y) } \\
\hline Purchased & 3230 & 3230 & 213 \\
\hline Recycled & 11,503 & 11,503 & 46,438 \\
\hline \multicolumn{4}{|l|}{ Utilities required (MWh/y) } \\
\hline Electricity "recycled" & 531 & 548 & 2092 \\
\hline Electricity purchased & 185 & 168 & / \\
\hline Heat "recycled" & 1700 & 1700 & 4968 \\
\hline Heat source purchased & / & / & / \\
\hline \multicolumn{4}{|l|}{ Sustainability item $(\$ / y)$} \\
\hline Economic profit & $-548,346$ & $-548,452$ & $-2,323,475$ \\
\hline Eco-profit & $-113,681$ & 321,269 & $2,802,824$ \\
\hline Social profit & 77,456 & 77,456 & 230,344 \\
\hline Sustainability profit & $-584,572$ & $-149,728$ & 709,692 \\
\hline Economic $^{+G H G}$ profit & $-500,291$ & $-498,191$ & $-2,157,453$ \\
\hline $\mathrm{CO}_{2}$ eq. emissions $(\mathrm{t} / \mathrm{y})^{\mathrm{a}}$ & -1807 & -1890 & -6241 \\
\hline Selected Site & I & I & I, II, III \\
\hline Dry matter content (\%) & 13 & 13 & $12.06|11.97| 11.91$ \\
\hline Methane content (\%) & 56.18 & 56.18 & $55.87|56.36| 56.92$ \\
\hline
\end{tabular}

avoided GHG emissions

${ }^{b}$ if not specified for each biogas supply network separated, results present the sum from both networks

poultry bedding $(9355.3 \mathrm{t} / \mathrm{y})$ is the dominant feedstock exploited in the maximized economic and economic ${ }^{+G H G}$ profits scenarios while poultry manure and poultry slurry both with an average quantity of 25,500 t/y are the dominant feedstocks used in the maximized sustainability profit situation.

In the same manner, the electricity generated in the maximized sustainability case $(23,967.7 \mathrm{MWh} / \mathrm{y})$ is about 3 times that produced in the maximized economic and economic $^{+G H G}$ profits cases (8368.4 MWh/y). Furthermore, the dry digestate produced in the maximized $P^{\text {Sus- }}$ tainability scenario $(48,748.7 \mathrm{t} / \mathrm{y})$ is 3.63 times the quantity obtainable in the economic and economic ${ }^{+\mathrm{GHG}}$ profits situations $(13,398.5 \mathrm{t} / \mathrm{y})$. Similarly, the heat generated in the maximized economic and economic ${ }^{+\mathrm{GHG}}$ profit cases are each about $34 \%(5954.8 \mathrm{MWh} / \mathrm{y})$ the amount generated when the sustainability profit is maximized (17, 377.6 MWh/y).

Considering the emissions given off or avoided, all economic, economic ${ }^{+\mathrm{GHG}}$ and sustainability profit objective cases present positive (unburdening) effects on the supply chain and are between $1807 \mathrm{t} \mathrm{CO}_{2}$ eq./y for the economic objective case, and $6241 \mathrm{t} \mathrm{CO}_{2}$ eq./y in the case of maximal sustainability profit. On the other hand, 
Table 2 Main results when maximizing different profits for biogas supply network with larger capacity

\begin{tabular}{|c|c|c|c|}
\hline & Max PEconomic & Max $P^{\text {Economic }}{ }^{+H G G}$ & Max $P^{\text {Sustainability } b}$ \\
\hline \multicolumn{4}{|l|}{ Feedstock (t/y) } \\
\hline Corn grain & 18,838 & 18,838 & 18,251 \\
\hline Corn silage & / & / & 1200 \\
\hline Corn stover & 12,844 & 12,844 & 12,444 \\
\hline Grass silage & 11,080 & 11,244 & 55,158 \\
\hline Poultry bedding & 4808 & 5635 & 1026 \\
\hline Poultry manure & 49,895 & 49,656 & 125,313 \\
\hline Poultry slurry & / & / & 32,413 \\
\hline Total feedstock & 97,464 & 98,216 & 245,804 \\
\hline \multicolumn{4}{|l|}{ Products } \\
\hline Electricity (MWh/y) & 34,730 & 34,925 & $43,376 \mid 43,437$ \\
\hline Heat (MWh/y) & 24,662 & 24,849 & $51,366 \mid 51,439$ \\
\hline Digestate ( $23 \%$ dry solids, t/y) & 76,493 & 77,106 & $90,468 \mid 91,332$ \\
\hline Corn grain (direct product) & 18,206 & 18,206 & 17,639 \\
\hline \multicolumn{4}{|l|}{ Water (t/y) } \\
\hline Purchased & 26,902 & 26,892 & 63,624 \\
\hline Recycled & 71,981 & 75,306 & 738,432 \\
\hline \multicolumn{4}{|l|}{ Utilities required (MWh/y) } \\
\hline Electricity "recycled" & 2197 & 2283 & 6968 \\
\hline Electricity purchased & 767 & 703 & / \\
\hline Heat "recycled" & 7039 & 7093 & 16,549 \\
\hline Heat source purchased & / & / & / \\
\hline \multicolumn{4}{|l|}{ Sustainability items $(\$ / y)$} \\
\hline Economic profit & $-659,523$ & $-660,736$ & $-3,675,154$ \\
\hline Eco-profit & $-993,356$ & $1,608,143$ & $6,302,895$ \\
\hline Social Profit & 147,697 & 148,441 & 334,676 \\
\hline Sustainability profit & $-1,505,181$ & $1,095,848$ & $2,962,417$ \\
\hline Economic $^{+G H G}$ profit & $-454,124$ & $-441,056$ & $-3,214,145$ \\
\hline $\mathrm{CO}_{2}$ eq. emissions $(\mathrm{t} / \mathrm{y})^{\mathrm{a}}$ & -7721 & -8259 & $-17,331$ \\
\hline Selected Site & I & । & I, III \\
\hline Dry matter content (\%) & 12.54 & 12.32 & $5.90 \mid 5.93$ \\
\hline Methane content (\%) & 57.55 & 57.53 & $55.85 \mid 55.93$ \\
\hline
\end{tabular}

avoided GHG emissions

${ }^{b}$ if not specified for each biogas supply network separated, results present the sum from both networks

Site I is the optimal location for the construction and operation of the anaerobic digestion plants, dewatering plants and $\mathrm{CHP}$ in the economic and economic ${ }^{+\mathrm{GHG}}$ profits scenarios while all three locations are selected in the sustainability profit case.

Additionally, it could be seen from Table 1 that a 13\% dry matter content is obtained in the economic and economic $^{+\mathrm{GHG}}$ profits scenario while an average dry matter content of $11.98 \%$ is gotten when the sustainability profit objective is considered. Moreover, a 56.18\% methane content is accrued in the economic and economic ${ }^{+\mathrm{GHG}}$ profits objective while an average of $56.38 \%$ methane content is obtained in the three anaerobic digestion plants selected in the sustainability profit objective scenario.

It is worth noting that the model in all scenarios, optimally selects the transportation mode that supports the three objectives. From L1 to L2, road transport by truck is selected. From L2 to L3, both biogas and wet digestates produced are shipped using pipelines. From L3 to L4, dry digestate is transported using trucks while electricity and heat are transported through transmission lines and pipelines. Recycling of water from dewatering plants and heat from L3 to L2 occurs via pipelines, and electricity through transmission lines. 


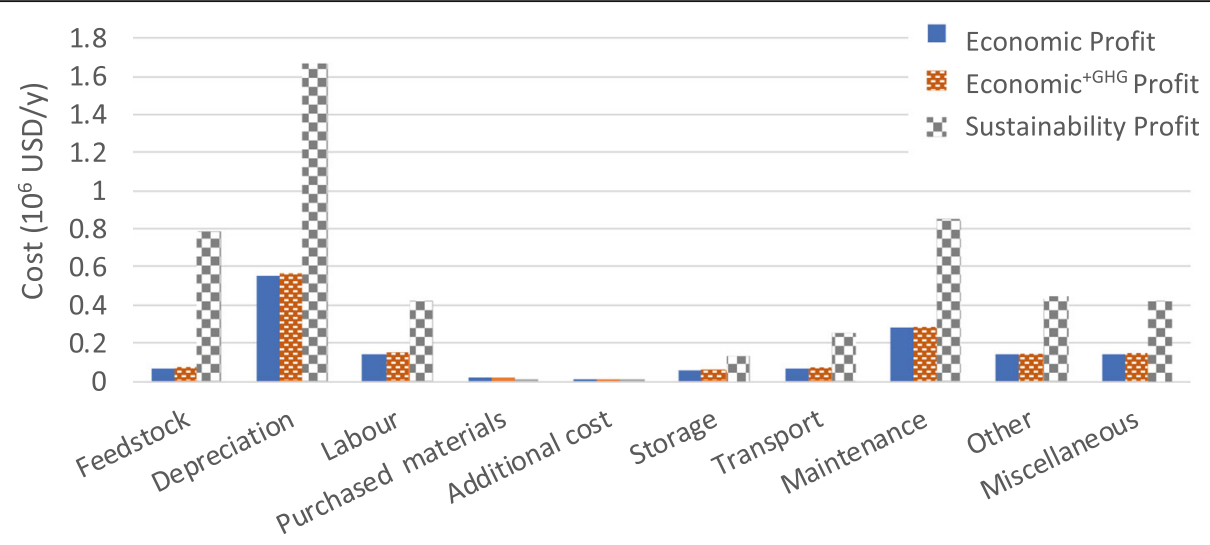

Fig. 6 Breakdown of costs incurred in the three objectives

A breakdown of the costs incurred in the three objectives (see Fig. 6) shows the dominance of depreciation cost in the three scenarios. The depreciation cost accounts for a little over a third of the total cost incurred in the three supply chains. Investment cost in the maximum economic and economic ${ }^{+\mathrm{GHG}}$ profit cases consists of the cost for anaerobic digester $\left(3.14 \times 10^{6} \$\right)$, CHP $\left(1.40 \times 10^{6} \$\right)$ and dewatering $\left(0.23 \times 10^{6} \$\right)$ while biogas holder is not selected. In case of maximal sustainability profit biogas holder is also not selected, while the cost for three anaerobic digesters is $9.25 \times 10^{6} \$$, for $\mathrm{CHP}$ plants it's $4.19 \cdot 10^{6} \$$ and dewatering is $0.81 \cdot 10^{6} \$$.

Furthermore, it is seen from Fig. 6 that the cost of obtaining extra materials (i.e. purchased materials) contributed a small portion to the total supply network expenditure. Purchased materials in the maximal economic and economic ${ }^{+\mathrm{GHG}}$ cases are only water and electricity used in anaerobic digesters, while in maximal sustainability case only water is purchased, and this indicates that electricity needed is recycled in the supply network (see also Table 1). One of the reasons for the low purchased material costs is the relatively low price of water and the pre-condition that water may be reused in the supply network. On the other hand, while all cost values in the sustainability profit objective are substantially higher than the other two objectives, the purchased material cost of the sustainability profit objective is the only cost attribute lower than those of the other two objectives. The reason for the low value of the purchased material cost in the sustainability profit objective is because only water is purchased in comparison to the water and electricity purchased in the economic and economic $^{+\mathrm{GHG}}$ profits objectives.

A small portion of total expenditure is also due to additional cost in the supply network when the feedstocks are partly transported between the zones. In this situation and for the three cases, corn stover is suggested to be transported between the zones. For instance, in the case of maximal economic and economic ${ }^{+G H G}$ profits corn stover is partly transported from zone II to zone I as seen in Fig. 7 which illustrates the areas intended for agricultural feedstocks when maximizing different objectives. It should also be noted that from the total area $\left(250 \mathrm{~km}^{2}\right)$ a maximum of $5 \%$ of the actual area $(50 \%$ in zones I and II and $37 \%$ in zone III) are set aside for feedstocks

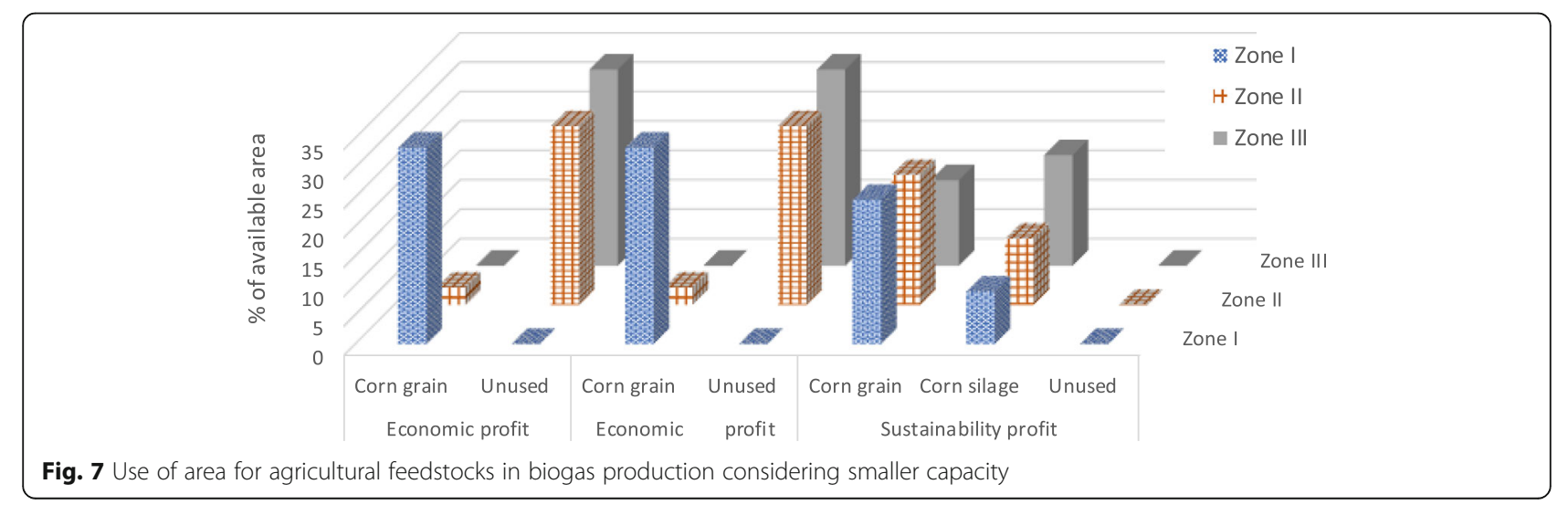




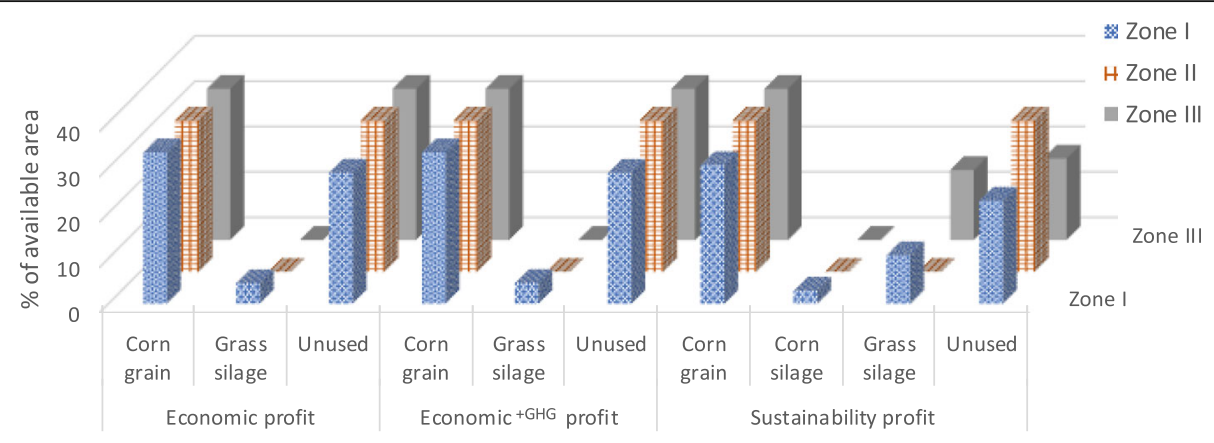

Fig. 8 Use of area for agricultural feedstocks in biogas production considering larger capacity

growing to meet the biogas generation, as previously stated. Hence, in the cases of maximal economic and economic $^{+\mathrm{GHG}}$ profits about $63.7 \%$ of the area is still unused, while in case of maximal sustainability profit, all the available area is suggested to be used for growing corn grain (and stover) and silage. Corn stover is used as a feedstock for biogas production, while grains are used for food.

In all the results obtained as shown in Table 1, biogas storage is not selected, and the electricity was produced at constant capacity. The main reasons are the relatively high investment cost of biogas holders (base case investment cost of 701,600 \$ and base case capacity of 3000 $\mathrm{m}^{3}$ of biogas stored is considered), higher investment cost for CHP plant in the case of higher capacity and backup for heat consumed in the anaerobic digestors are required.

Table 2 further illustrates the results obtained when maximizing different profits in the situation whereby the average capacity of electricity production is within the range of $4.8 \mathrm{MW}$ and $5.2 \mathrm{MW}$.

In a similar vein as the $1 \mathrm{MW}$ demand capacity scenario (see Table 1), the total feedstocks in the economic and economic ${ }^{+G H G}$ profit objectives each exploit approximately the same quantity of feedstocks $(98,000 \mathrm{t} / \mathrm{y})$ which is about $40 \%$ of the quantity of feedstocks utilized in the sustainability profit case $(245,804 \mathrm{t} / \mathrm{y})$.
The Site I is the optimally selected location for anaerobic digestion plants, dewatering plants and $\mathrm{CHP}$ for the economic and economic ${ }^{+G H G}$ profits objectives while Sites I and III are now chosen to meet maximal sustainability profit objective. Besides the selection of corn stover and silage as agricultural feedstocks, grass silage is also selected because it may be grown on marginal lands (in parks, riverbanks, road verges, and other lands). For grass silage, it is assumed that it could be grown on up to $50 \%$ of area present in zones I and II and on up to $37 \%$ of the area in zone III. The use of area intended for agricultural feedstocks in biogas supply network for the case of larger capacity and three objectives is shown in Fig. 8. The unused area in Fig. 8 is attributed to the area that may be additionally used for grass silage growing while the area that may be used for crops is fully utilised by corn grains and silage.

As in the case of smaller capacity biogas production, most of the water used for anaerobic digesters come from a recycled stream. For instance, in the case of maximal sustainability profit, the quantity of recycled water is $738,431.7 \mathrm{t} / \mathrm{y}$, mainly due to lower dry matter content (5.9\%) in fermenters as opposed to approximately $12 \%$ dry matter content in the case of the smaller plant's capacity. Most of the electricity used for the plant comes from "recycled" produced

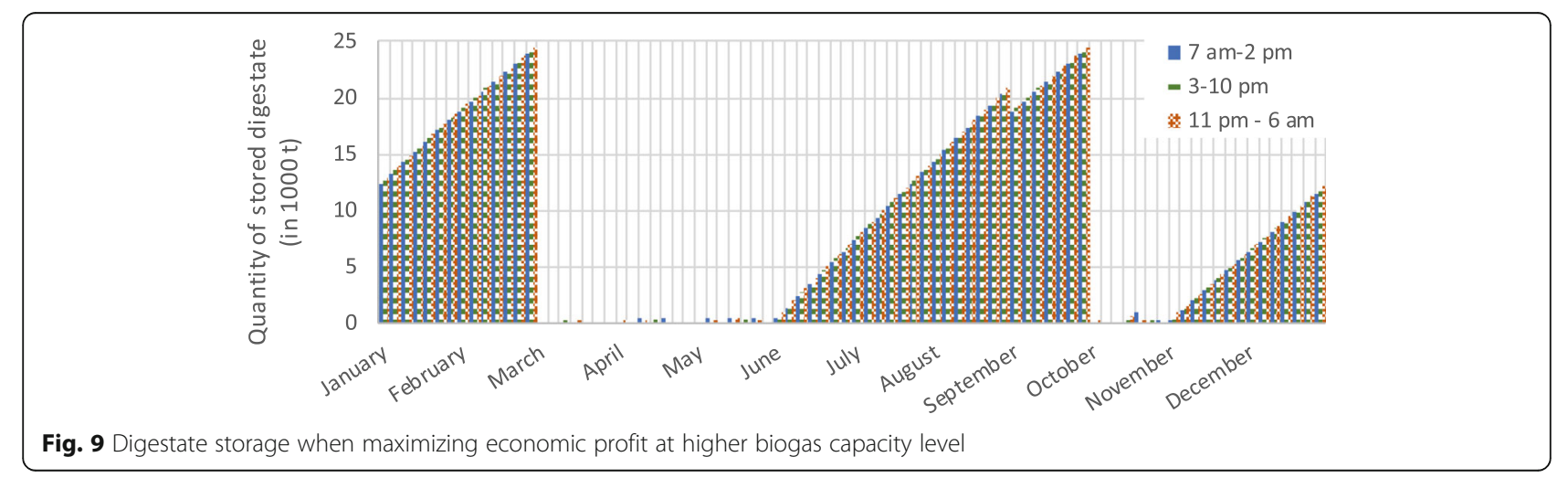




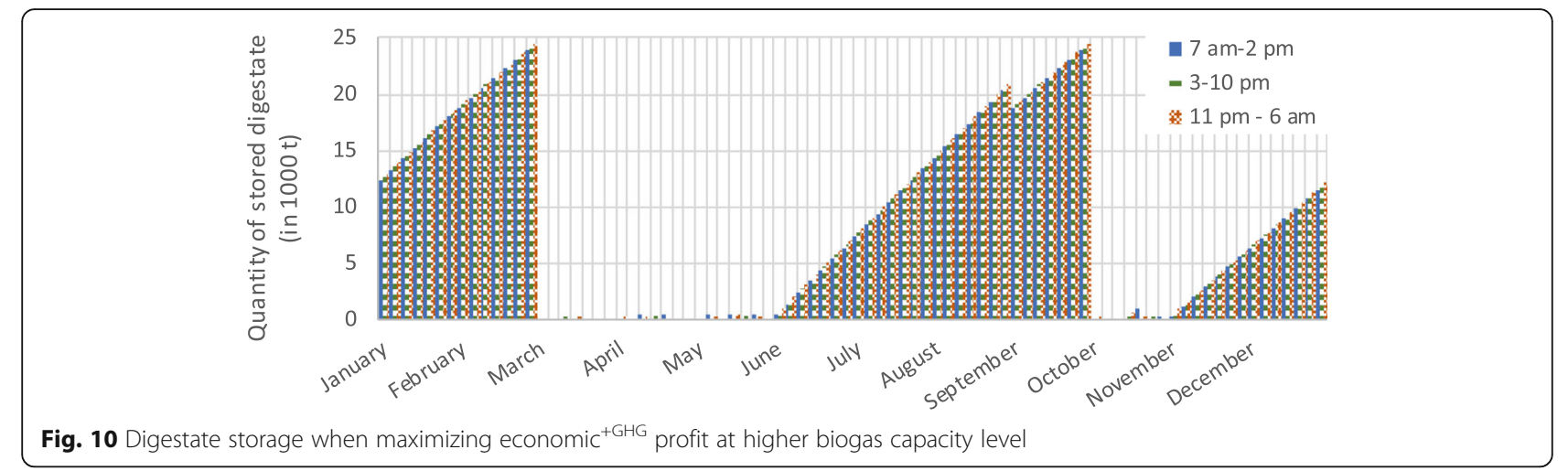

electricity of which the maximal sustainability profit case indicates all the electricity utilized being of renewable origin. Also, the heat required for the digesters is "recycled" in all the cases considered.

Furthermore, from Table 2, it is noticed that in the three cases, economic and economic ${ }^{+\mathrm{GHG}}$ profits present negative values while on the other hand, social profits are positive in all the cases. The eco- and sustainability profits are negative when economic profit is maximized but gives positive values in the cases of maximal economic ${ }^{+\mathrm{GHG}}$ and sustainability profits. In the maximal economic profit scenario, it is suggested that much more digestate is stored in comparison to the digestate stored when economic $^{+G H G}$ profit is maximized (see Figs. 9 and 10), and thus the burden related to the digestate storage is higher in the case of maximal economic profit $\left(3.719 \cdot 10^{6} \$ / y\right.$ vs $\left.1.732 \cdot 10^{6} \$ / y\right)$. Figure 9 hence shows digestate storage when economic profit is maximized, while Fig. 10 shows digestate storage when economic ${ }^{+\mathrm{GHG}}$ profit is maximized, both at the higher capacity of biogas supply networks. However, in the case of maximal sustainability profit, digestate storage is comparably lower (see Fig. 11), since two plants are selected.

\section{Sensitivity analysis for improved profitability of biogas production}

Since the results from all economic, economic ${ }^{+G H G}$ and sustainability profits present economic loss (see Tables 1 and 2), sensitivity analysis is additionally carried out to investigate possible improvements regarding the profitability of biogas production. Four additional scenarios are hereby put forward: i) the scenario whereby in calculating the economic ${ }^{+\mathrm{GHG}}$ profit, the prices of GHG emissions are steadily increased from $26.6 \$ / \mathrm{t}$ (or $20 € / \mathrm{t}$ ) (allowances in $\mathrm{EU}$ ETS [40]) up to $154.28 \$ / \mathrm{t}$ (or $116 € / \mathrm{t}$ ) (eco-costs of global warming [32]), ii) the scenario whereby all the electricity auction trading prices are simultaneously multiplied by certain factors to know how much subsidies should be included on top of market prices of electricity to make it profitable, iii) the scenario whereby for a selected month where only the hours are merged into 3 shift periods the cost of biogas storage is reduced in order to study the relationship between the biogas storage cost and biogas storage capacity and electricity production based on averaged auction trading prices of electricity, and (iv) the scenario in which biogas plant capacity is varied from $1 \mathrm{MW}$ to $5 \mathrm{MW}$ to study how capacity affects the

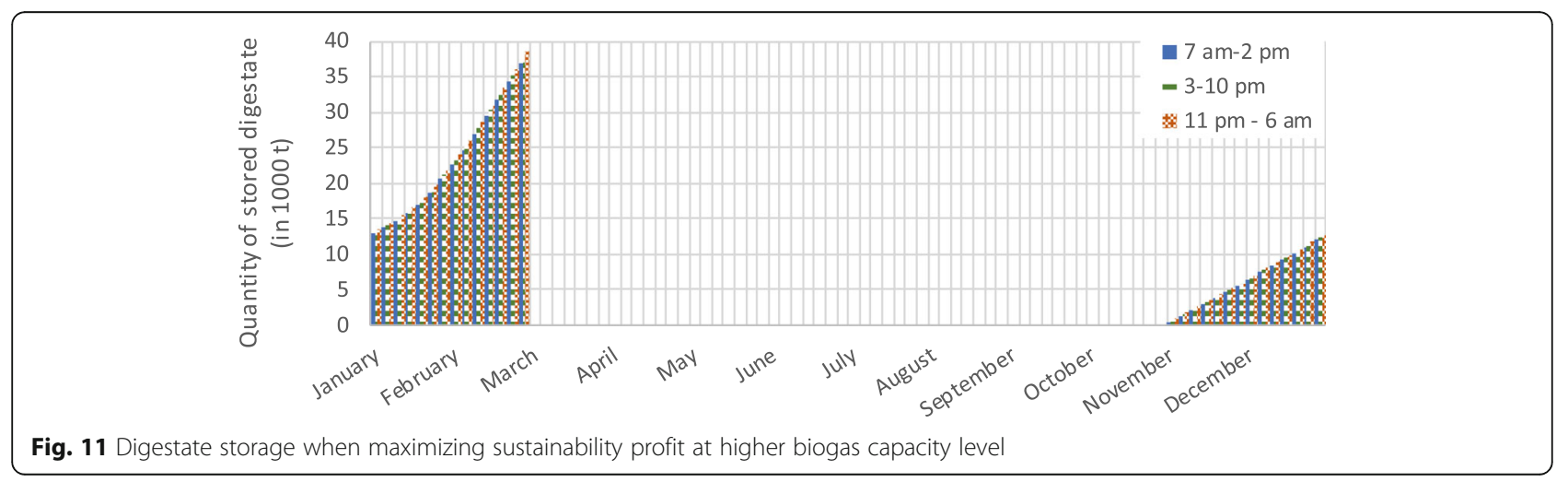




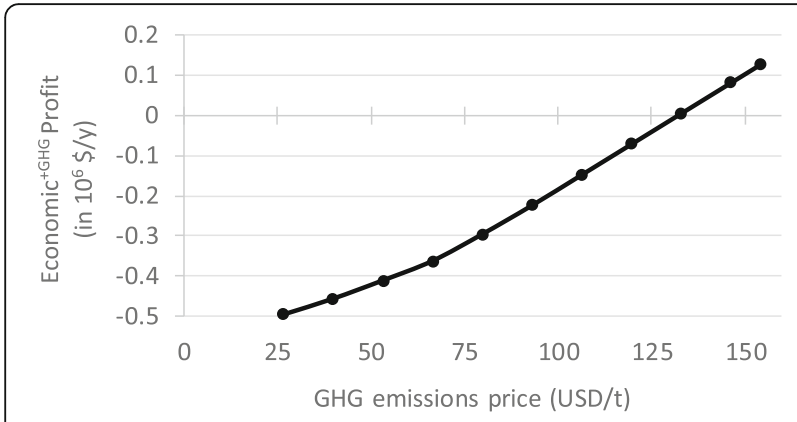

Fig. 12 Effects of GHG emissions price variation on economic $^{+G H G}$ profit

economic profit (loss). In a situation of the relatively high cost of biogas storage, biogas storage was never selected, and the electricity was always produced at constant capacity.

\section{Maximizing economic ${ }^{+G H G}$ profit while increasing prices of GHG emissions}

Figure 12 illustrates the effects of steadily increasing the GHG emissions prices on the economic ${ }^{+\mathrm{GHG}}$ profit (see Eq. (15)) when the average capacity of 1 MW of electricity production is considered. At 20 $€ / \mathrm{t}$ GHG emission price (26.6 \$/t with the considered conversion rate), economic ${ }^{+\mathrm{GHG}}$ profit of approximately $-498,191 \$ / y$ (see also Table 1 ) is obtained (economic loss). With a steady increase of GHG emissions price, it is seen that a breakeven value is obtained at about $133 \$ / \mathrm{t}$. Furthermore, a hike of the GHG emissions price above $100 € / \mathrm{t}$ presents positive effects on the economic ${ }^{+G H G}$ profit (economic profit including benefits from avoided GHG emissions). From this, it could be concluded that biogas production could be competitive at auction trading prices when the benefits of GHG unburdening would be recognised and when the price of GHG emissions would be higher than $100 € / \mathrm{t} \mathrm{CO}_{2}$ eq.

\section{Maximizing economic profit while increasing auction trading prices of electricity}

In this section, the effects of increasing the auction trading prices of electricity as it affects the maximized economic profit are put forward. It might not be expected that the activities which have net unburdening effects on the environment would get benefits from it. Due to this, the auction trading prices are multiplied by a certain factor, which could be interpreted as how much subsidies may be required for the electricity generation from biogas to be profitable. Figure 13 shows that an increase in auction trading prices of electricity causes an increase in

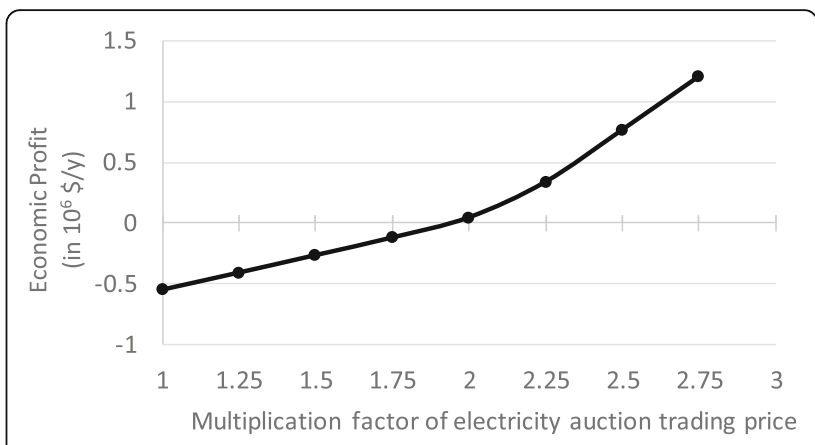

Fig. 13 Effects of electricity auction trading prices variation on economic profit

economic profit (lower biogas capacity level). For instance, in the base case scenario where there is no change in auction trading price, a negative economic profit (approximately of 548,346 \$/y economic loss) is incurred as shown in Table 1. In the instance, when the auction trading price is doubled, a breakeven value is obtained in the biogas supply network. Moreover, an increase beyond the doubled auction trading price presents positive economic profit values. As a backdrop of this, it could be concluded that for the biogas supply network to be profitable, either subsidy in the amount of auction trading prices should be provided or the carbon benefit should be at least $133 \$ / \mathrm{t}$.

\section{Influence of shorter period and the investment cost of biogas storage on electricity production}

As shown in Additional file 1: Tables S13-S23, averaging electricity prices based on 7 periods a month alleviates the variability of electricity prices. For this reason, an additional scenario is performed whereby for a selected month, each day in the month is considered while the hours are merged into 3 shift periods. Such a scenario is performed for the average capacity of $1 \pm 0.1 \mathrm{MW}$ of electricity produced and by maximizing the economic profit where only one plant at Site I is selected. In this scenario, the variations in electricity prices are slightly better highlighted, as can be seen from Fig. 14 which shows an example of electricity prices for the three periods considered in each day for the month of January (based on the data from BSP South Pool Energy Exchange (2008) and considered conversion rate). In this sense, January is considered as an illustration. It should be noted that this scenario is performed for the specific month separately and yearly due to the computational time required to solve such a problem.

From Fig. 14, the prices in January are on average the highest within the afternoon/evening period ( $3 \mathrm{pm}-10$ $\mathrm{pm})$, and lowest during the night period (11 pm $-6 \mathrm{am})$. 


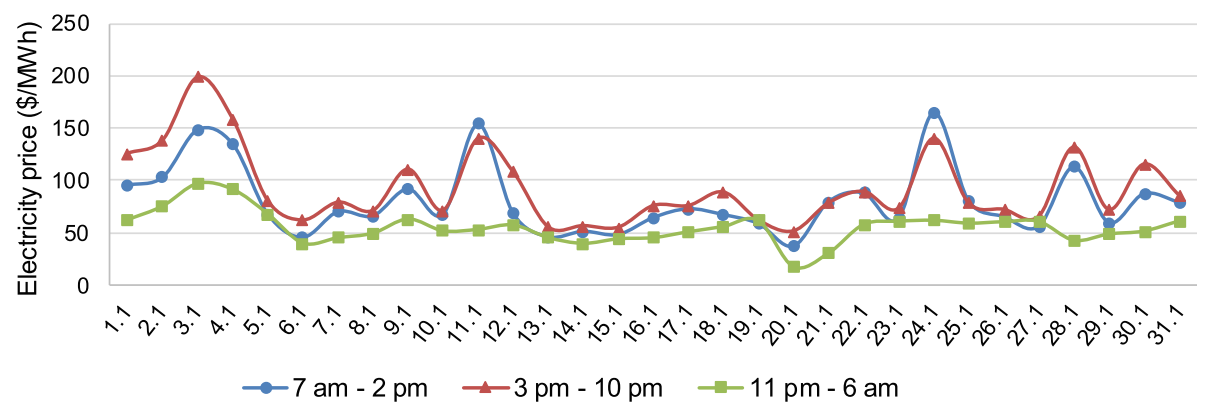

Fig. 14 Electricity prices when considering 3 periods a day for January

On average the prices in the afternoon/evening are 1.71 times higher than that of the night period and in the morning 1.49 times higher than during the night. Note that in Fig. 14, 1.1, 2.1, 3.1, represent day 1 in January, day 2 in January, day 3 in January, etc.

However, despite the relatively significant differences in the prices, again biogas storage was not selected, and the electricity was produced at constant capacity. As it was stated previously, the main reason is the high investment cost of biogas holders, but also higher investment cost incurred in acquiring the CHP plant and a backup is required for the heat consumed by the plant itself.

To study the relationship between the volume of biogas stored and electricity production, investment cost for biogas storage was thus reduced. It was found that the biogas storage is selected when the base case price (with a considered base case capacity of $3000 \mathrm{~m}^{3}$ of biogas stored) is reduced from investment cost of 701,600 \$ to $300,000 \$$ or lower (see also Additional file 1: Figure S1). Figure 15, which is for the month of January, shows how a reduction in the investment costs of the biogas storage facility affects the daily storage of biogas. Hence, a reduction of investment cost for the biogas holder presents maximum daily period storage of $3154 \mathrm{~m}^{3}$ occurring during the night period $(11 \mathrm{pm}-6 \mathrm{am})$. The storage pattern follows the electricity prices in that in the night period when electricity prices are low, the amount of biogas stored is the highest, and when electricity prices are higher (in the afternoon period), almost no biogas is stored. On the other hand, the prices in the morning are "in-between", and thus also the amounts of stored biogas are "in-between" the afternoon and night periods.

Figure 16 shows electricity production in the month of January, where the electricity is produced in the afternoons/evenings at the highest capacity levels (9.54 MW), while in the morning hours electricity produced fluctuates between $9.6 \mathrm{MW}$ and $2.8 \mathrm{MW}$. On the other hand, apart from 6 days $(14,29,21,27,28$ and 31) in January, little or no electricity is produced. It is worth stating that the average daily electricity generated in January is $19.6 \mathrm{MWh}$ /day (accounting for $93.5 \%$ of operating time and between $1.95 \times 10^{6}$ and $2.38 \times 10^{6} \mathrm{~m}^{3} / \mathrm{y}$ of methane produced), of which $48.5 \%$ on average is produced in the $3 \mathrm{pm}-10 \mathrm{pm}$ period ( $9.51 \mathrm{MWh} /$ day), $42.2 \%$ in the $7 \mathrm{am}-2 \mathrm{pm}$ period (8.32 MWh/day) and only $9.1 \%$ during the night period (1.78 MWh/day). Some variations from the "typical" trend could be seen during the days 1, 14-15, 20-22, 27-28 and 31 , when electricity production is either lower (morning hours) or greater (night hours). This scenario occurs mainly in the days when biogas is not stored (days 14, 20, 21, 27, 31), as shown also from Fig. 15.

Similarly, Figs. 17 and 18 show the biogas storage and electricity production profiles for the month of December which is the month whereby the electricity prices also have negative values in some hours.

Figure 17 displays the maximum daily period storage as $2877 \mathrm{~m}^{3}$, which occurs during the night

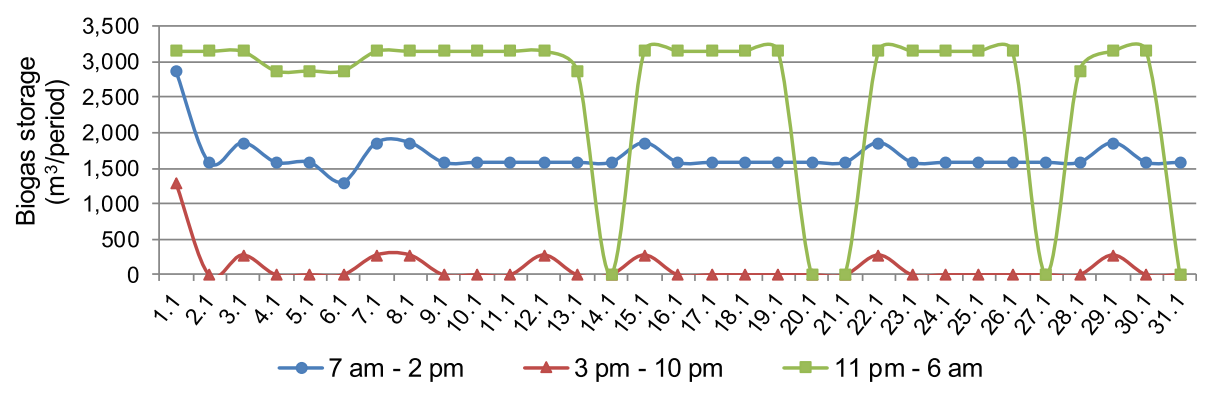

Fig. 15 Biogas storage in January when the biogas holder investment cost is reduced from 701,600\$ to $300,000 \$$ 


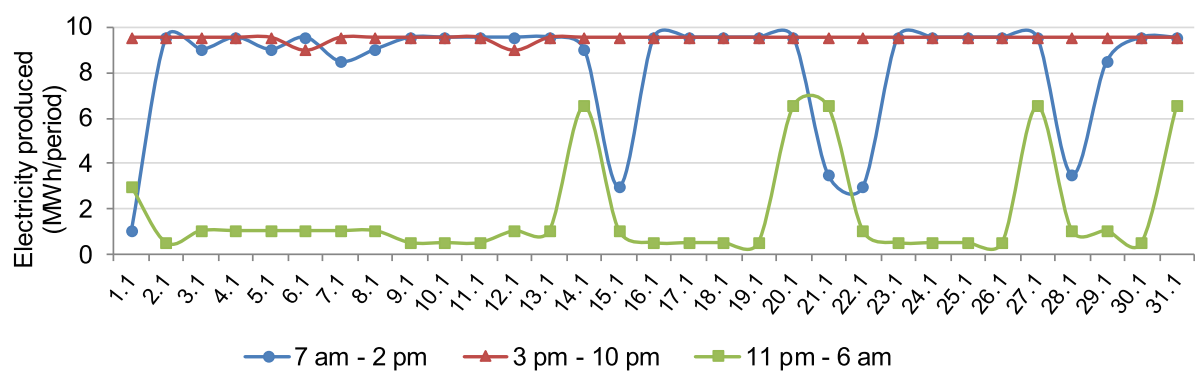

Fig. 16 Electricity production in January when the biogas holder investment cost is reduced to $300,000 \$$

period $(11 \mathrm{pm}-6 \mathrm{am})$, and on certain days in the other two periods. Figure 18 also illustrates that electricity is mostly produced during the day periods. However, significant "disturbances" in the patterns could be seen in the days between 6 and 10 December and 23-26 December. During these days, electricity prices are either the highest or the lowest, as shown in Fig. 3.

Considering the scenario where investment cost is further reduced, more significant differences in biogas storage and electricity production patterns are obtained and higher amounts of biogas are to be stored. For example, if the base case cost of biogas holder is reduced to $2000 \$$, the model solution shows that $3430 \mathrm{~m}^{3}$ of biogas is maximally stored in January, while still the same amount $\left(2877 \mathrm{~m}^{3}\right)$ is stored in December. With the decrease of the investment cost for biogas storage, more biogas is indicated to be stored.

\section{Variation of biogas plant capacity with economic profit (loss)}

This scenario considers a situation whereby the biogas plant capacity is varied from $1 \mathrm{MW}$ to $5 \mathrm{MW}$ with increments of $500 \mathrm{~kW}$ as illustrated in Fig. 19.

From Tables 1 and 2, it is noted that at $1 \mathrm{MW}$ capacity of the biogas plant an economic loss of about 550 , $000 \$ / y$ is incurred in the supply chain which is $13 \%$ less than that incurred in the $5 \mathrm{MW}$ biogas plant capacity. However, considering Fig. 19, it is evident that when biogas capacity is $3 \mathrm{MW}$, the lowest economic loss $(349,825 \$ / y)$ is accrued in the supply chain. The value of economic loss obtained in the $3 \mathrm{MW}$ capacity scenario may be as a result of the selection of relatively cheaper feedstocks, such as poultry manure $(28,719 \mathrm{t} / \mathrm{y})$ and corn stover $(12,844 \mathrm{t} / \mathrm{y})$ and due to economy of scale. At capacities higher than $3 \mathrm{MW}$, the more expensive grass silage is selected to satisfy the consumption and restrictions in terms of available area for biogas production.

\section{Conclusions}

This study presents a model showcasing the effects of economic profit, sustainability profit and economic ${ }^{+\mathrm{GHG}}$ profit on the supply chain network production of electricity based on two capacities (1 MW and $5 \mathrm{MW}$ ) over hourly, daily, and monthly timeframes. An illustrative case study of three sites in Slovenia is used and results show negative economic values obtained for the three objectives considered.

The effects of increasing the GHG emission prices when maximizing economic ${ }^{+\mathrm{GHG}}$ profits gives a breakeven GHG emissions price of $133 \$ / t$. Moreover, a sensitivity analysis involving the variation of the auction trading prices of electricity against maximizing the economic profit shows that the breakeven value

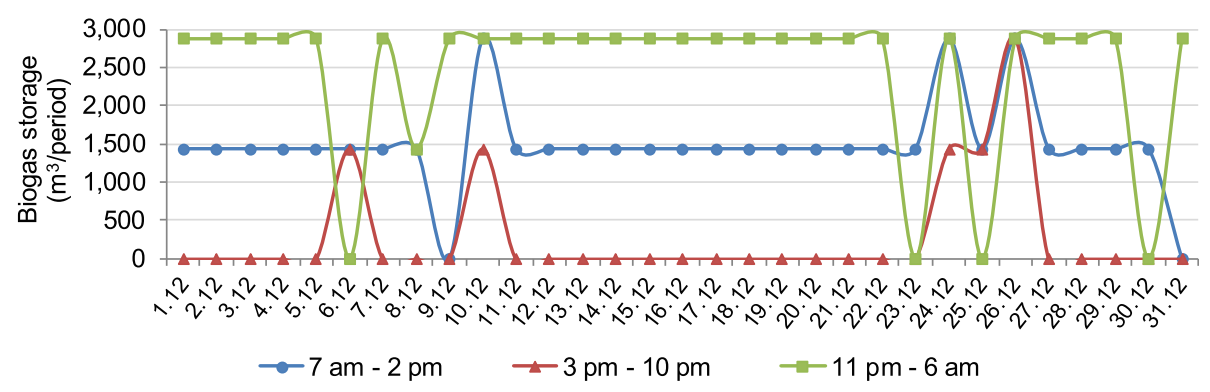

Fig. 17 Biogas storage in December when the biogas holder investment cost is decreased to $300,000 \$$ 


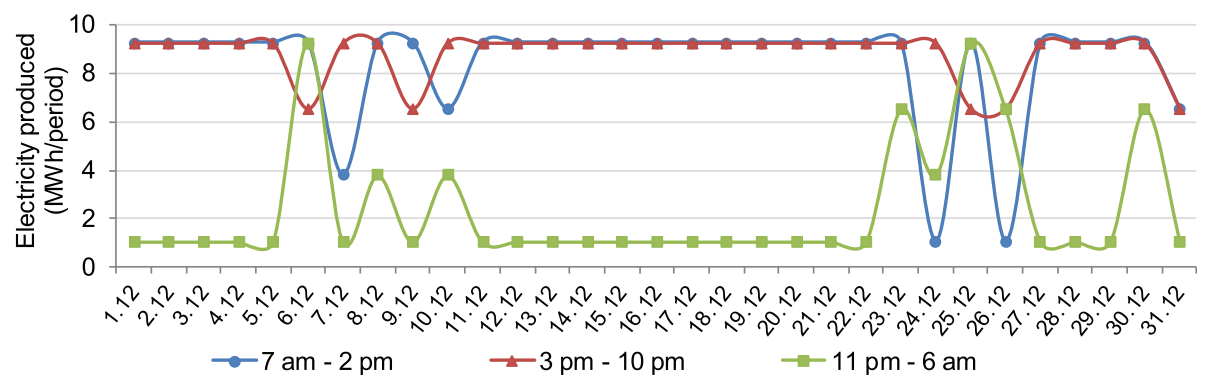

Fig. 18 Electricity production in December when the biogas holder investment cost is decreased to $300,000 \$$

for economic profit may only be obtained beyond the doubling of the auction trading prices. Furthermore, the variation of biogas plant capacity with economic profit showed the lowest economic loss obtained at the $3 \mathrm{MW}$ capacity.

In future studies, the model will be extended to integrate electricity generation from solar and wind energy sources. Furthermore, other bioenergy products in the form of bioethanol, biodiesel and other may also be included which extends the variety of products, raw materials and conversion technologies employed. Moreover, a comparative analysis of the results obtained in this study could also be made for another region or country. Finally, the study regarding processing the lower quality by-product (digestate) into more valuable products will be performed in order to further investigate the possible opportunities for improving profitability of biogas production while considering auction trading prices of electricity. As there are many uncertainties involved in different decisions (such as raw material composition and its availability, biogas yield, prices and other), flexible synthesis of biogas supply network could be performed. Methodology for sustainable design of supply networks with a larger number of uncertain parameters proposed recently [49] and applied to biogas supply network [13] could be used for the case of biogas supply networks considering multiple objectives and auction trading prices of electricity.

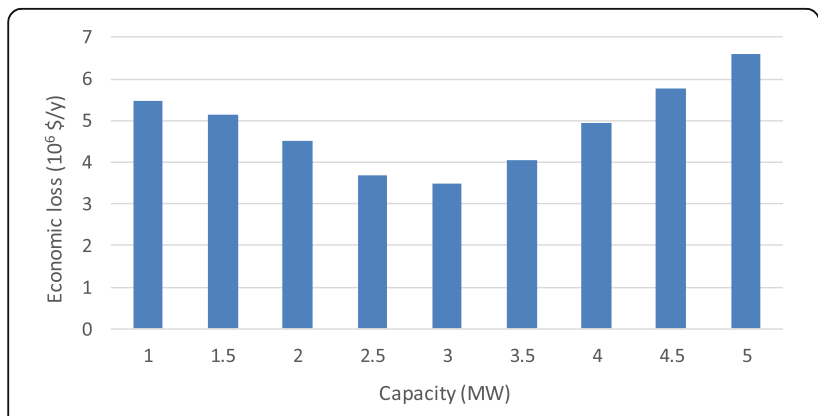

Fig. 19 Variation of biogas plant capacity with economic profit

\section{Supplementary information}

Supplementary information accompanies this paper at https://doi.org/10 1186/s42480-019-0025-5.

Additional file 1: PART A. Data: Table S1. Auction Trading Prices for January (in €/MWh). Table S2. Auction Trading Prices for February (in $€ / M W h$ ). Table S3. Auction Trading Prices for March (in €/MWh). Table S4. Auction Trading Prices for April (in $€ / M W h)$. Table S5. Auction Trading Prices for May (in €/MWh). Table S6. Auction Trading Prices for June (in $€ / M W h$ ). Table S7. Auction Trading Prices for July (in $€ / M W h$ ). Table S8. Auction Trading Prices for August (in $€ / M W h$ ). Table S9. Auction Trading Prices for September (in €/MWh). Table S10. Auction Trading Prices for October (in €/MWh). Table S11. Auction Trading Prices for November (in €/MWh). Table S12. Auction Trading Prices for December (in $€ / M W h$ ). Table S13. Considered (Averaged) Auction Trading Prices for January (in $\$ / k W h$ ). Table S14. Considered (Averaged) Auction Trading Prices for February (in $\$ / k W h$ ). Table S15. Considered (Averaged) Auction Trading Prices for March (in $\$ / \mathrm{kWh}$ ). Table S16. Considered (Averaged) Auction Trading Prices for April (in $\$ / k W h$ ). Table S17. Considered (Averaged) Auction Trading Prices for May (in $\$ / k W h$ ). Table S18. Considered (Averaged) Auction Trading Prices for June (in $\$ / \mathrm{kWh}$ ). Table S19. Considered (Averaged) Auction Trading Prices for July (in $\$ / k W h$ ). Table S20. Considered (Averaged) Auction Trading Prices for August (in $\$ / \mathrm{kWh}$ ). Table S21. Considered (Averaged) Auction Trading Prices for September (in $\$ / \mathrm{kWh}$ ). Table $\mathbf{S 2 2}$. Considered (Averaged) Auction Trading Prices for October (in $\$ / \mathrm{kWh}$ ). Table $\mathbf{S 2 3}$. Considered (Averaged) Auction Trading Prices for November (in $\$ / k W h$ ). Table $\mathbf{S 2 4 .}$ Considered (Averaged) Auction Trading Prices for December (in $\$ / \mathrm{kWh}$ ). Table S25. Coefficient for avoided GHG emissions for material $p$. Table S26. GHG emission coefficient of acquisition and consumption of material $p$. Table S27. GHG emission coefficient for transport of material p. Table S28. Eco-benefit coefficient of material $p$. Table S29. Eco-cost coefficient of material $p$. Table $\mathbf{S 3 0}$. Eco-cost coefficient related to transport of material $p$. Table S31. Parameters used to calculate Social Profit. Figure S1. Correlation for capital cost for biogas holder. PART B. Nomenclature.

\section{Abbreviations}

1G: First-generation; 2G: Second-generation; 3G: Third-generation AD: Anaerobic Digestion; BIOSOM: Biogas Supply Optimization Model; CHP: Combined Heat and Power plants; EISA: Energy Independence and Security Act; ETS: Emission Trading Scheme; EU: European Union; EVR: Ecocosts / Value Ratio; GHG: Greenhouse gas emissions; kW: Kilowatt; L1: First layer; L2: Second layer; L3: Third layer; L4: Fourth layer; LCA: Life Cycle Assessment; LCIA: Life Cycle Impact Assessment; MILP: Mixed Integer Linear Programming; MW: Megawatt; MWe: Megawatt of electricity; NPV: Net Present Value; TAC: Total Annualized Cost

\section{Acknowledgments}

Not applicable.

\section{Authors' contributions}

JE and KZ collected the data, prepared the optimization model and wrote the first draft of the manuscript. LC supervised the work and analysed the 
data and the model. All authors discussed the findings, contributed to revising the manuscript and read and approved the final manuscript.

\section{Funding}

The authors are grateful for the support of funds from the Research Office of the University of Cape Town, the Engineering and the Built Environment Faculty of the University of Cape Town (UCT), the National Research Foundation of South Africa under Grant number 87744, the Nigeria Atomic Energy Commission, Slovenian Research Agency (research core funding No. P2-0412 and P2-0032, project J7-1816 and PhD research fellowship MR39209), Slovenia-Croatia bilateral project Integration of Renewable Energy within Energy Systems - INTEGRES and the Erasmus+ programme of the European Union.

\section{Availability of data and materials}

All data are provided in the manuscript or cited in the references.

\section{Competing interests}

The authors declare that they have no competing interests.

\section{Author details}

${ }^{1}$ Nuclear Power Plant Development (NPPD) Directorate, Nigeria Atomic Energy Commission, Abuja, FCT, Nigeria. ${ }^{2}$ Department of Chemical Engineering, University of Cape Town, Private Bag X3, Rondebosch, Cape Town 7701, South Africa. ${ }^{3}$ Faculty of Chemistry and Chemical Engineering, University of Maribor, Smetanova ulica 17, 2000 Maribor, Slovenia.

\section{Received: 16 September 2019 Accepted: 16 December 2019}

\section{Published online: 08 January 2020}

\section{References}

1. Acheampong M, Ertem FC, Kappler B, Neubauer P. In pursuit of sustainable development goal (SDG) number 7: will biofuels be reliable? Renew Sust Energ Rev. 2017;75:927-37.

2. Yue D, You F, Snyder SW. Biomass-to-bioenergy and biofuel supply chain optimization: overview, key issues and challenges. Comput Chem Eng. 2014; 66:36-56.

3. Hegnsholt E, Unnikrishnan S, Pollmann-Larsen M, Askelsdottir B, Gerard M: Tackling the 1.6-billion-ton food loss and waste crisis < provisioncoalition. com/Assets/ProvisionCoalition/Documents/Library\%20Content/Food\%2 OWaste\%20Management/BCG-Tackling-the-1.6-Billion-Ton-Food-Waste-CrisisAug-2018\%20(1) tcm74-200324.pdf>; Accessed 22 Dec 2018. 2018.

4. United Nations: Goal 12: Ensure sustainable consumption and production patterns <un.org/sustainabledevelopment/sustainable-consumption-production/>; Accessed 8 Jan 2019. 2018

5. EAl: Policies in India <eai.in/ref/ae/bio/pol/biomass_policies.html>; Accessed 9 Nov 2018. 2018

6. Ghana Energy Commission: Draft Bioenergy Policy for Ghana < cleancookingalliance.org/binary-data/RESOURCE/file/000/000/69-1.pdf>; Accessed 12 Jan 2019. 2010.

7. European Commission: Biofuels <ec.europa.eu/energy/en/topics/renewableenergy/biofuels/overview>; Accessed 3 Sept 2019. 2019.

8. National Energy Administration: China: 13th five-year plan for bioenergy development. <policy.asiapacificenergy.org/node/3041>; Accessed 3 Sept 2019. 2019.

9. Sharma B, Ingalls RG, Jones $C L$, Khanchi A. Biomass supply chain design and analysis: basis, overview, modeling, challenges, and future. Renew Sust Energ Rev. 2013;24:608-27.

10. Gaurav N, Sivasankari S, Kiran GS, Ninawe A, Selvin J. Utilization of bioresources for sustainable biofuels: a review. Renew Sust Energ Rev. 2017; 73:205-14

11. Ho DP, Ngo HH, Guo W. A mini review on renewable sources for biofuel. Bioresour Technol. 2014;169:742-9.

12. El-Halwagi AM, Rosas C, Ponce-Ortega JM, Jiménez-Gutiérrez A, Mannan MS, El-Halwagi MM. Multiobjective optimization of biorefineries with economic and safety objectives. AICHE J. 2013;59(7):2427-34.

13. Zirngast $K$, Čuček L, Zore Ž, Kravanja Z, Novak Pintarič Z. Synthesis of flexible supply networks under uncertainty applied to biogas production. Comput Chem Eng. 2019;129:106503.
14. Emara IA, Gadalla MA, Ashour FH. Supply chain design network model for biofuels and chemicals from waste cooking oil. Chem Eng Trans. 2018;70: 433-8.

15. Ivanov BB, Dzhelil YR, Ganev El, Dobruzhaliev DG. Multi-period model of sustainable integrated hybrid first and second generation bioethanol supply chains. Chem Eng Trans. 2018;70:289-94.

16. Díaz-Trujillo LA, Nápoles-Rivera F. Optimization of biogas supply chain in Mexico considering economic and environmental aspects. Renew Energy. 2019;139:1227-40.

17. Egieya J, Čuček L, Isafiade A, Kravanja Z. Synthesis of Supply Networks over Multiple Time Frames: A Case Study of Electricity Production from Biogas. Comput Aided Chem Eng. 2017;40:1447-52.

18. Mousavi Ahranjani P, Ghaderi SF, Azadeh A, Babazadeh R. Hybrid multiobjective robust Possibilistic programming approach to a sustainable bioethanol supply chain network design. Ind Eng Chem Res. 2018;57(44):15066-83.

19. Čuček L, Martín M, Grossmann IE, Kravanja Z. Multi-period synthesis of optimally integrated biomass and bioenergy supply network. Comput Chem Eng. 2014;66:57-70.

20. Egieya JM, Cuček L, Zirngast K, Isafiade AJ, Pahor B, Kravanja Z. Biogas supply chain optimization considering different multi-period scenarios. Chem Eng Trans. 2018;70:985-90

21. Mutenure M, Čuček L, Egieya J, Isafiade AJ, Kravanja Z. Optimization of bioethanol and sugar supply chain network: a south African case study. Clean Techn Environ Policy. 2018;20(5):925-48.

22. Wang B, Gebreslassie BH, You F. Sustainable design and synthesis of hydrocarbon biorefinery via gasification pathway: integrated life cycle assessment and technoeconomic analysis with multiobjective superstructure optimization. Comput Chem Eng. 2013;52:55-76.

23. How BS, Lam HL. Integrated biomass supply chain in Malaysia: a sustainable strategy. Chem Eng Trans. 2017;61:1573-8.

24. Boström M. A missing pillar? Challenges in theorizing and practicing social sustainability: introduction to the special issue. Sustainability: Sci Pract Policy. 2012;8(1):3-14.

25. You F, Tao L, Graziano DJ, Snyder SW. Optimal design of sustainable cellulosic biofuel supply chains: multiobjective optimization coupled with life cycle assessment and input-output analysis. AICHE J. 2012:58(4):1157-80.

26. Zore Ž, Čuček L, Kravanja Z. Syntheses of sustainable supply networks with a new composite criterion-sustainability profit. Comput Chem Eng. 2017; 102:139-55.

27. Zore Ž, Čuček L, Kravanja Z. Synthesis of sustainable production systems using an upgraded concept of sustainability profit and circularity. J Clean Prod. 2018;201:1138-54

28. Egieya JM, Čuček L, Zirngast K, Isafiade AJ, Pahor B, Kravanja Z. Synthesis of biogas supply networks using various biomass and manure types. Comput Chem Eng. 2019;122:129-51.

29. Vogtländer J, Baetens B, Bijma A, Brandjes E, Lindeijer E, Segers M, Witte F, Brezet J, Hendriks CF. LCA-based assessment of sustainability the eco-costs. Value Ratio: EVR Delft; 2009.

30. Čuček $L$, Drobež $R$, Pahor B, Kravanja Z. Sustainable synthesis of biogas processes using a novel concept of eco-profit. Comput Chem Eng. 2012;42: 87-100.

31. Market Insider: CO2 European Emission Allowances <markets. businessinsider.com/commodities/co2-european-emission-allowances> Accessed 2 Sept 2019.

32. Delft University of Technology: The Model of the Eco-costs / Value Ratio (EVR) <ecocostsvalue.com/EVR/model/theory/subject/2-eco-costs.html>; Accessed 2 Sept 2019. 2019.

33. BSP South Pool Energy Exchange: Day-ahead Trading Results, Auction Trading <bsp-southpool.com/day-ahead-trading-results-si.html >; Accessed 2 Sept 2019. 2019.

34. Agriculture Institute of Slovenia: Biogas substrates in Slovenia <arhiv.kis.si/ datoteke/File/kis/SLO/MEH/Biogas/SUBSTRATNA_LISTA_2008.pdf>; Accessed: 3 Sept 2019. 2008

35. Patrizio P, Leduc S, Chinese D, Dotzauer E, Kraxner F. Biomethane as transport fuel-a comparison with other biogas utilization pathways in northern Italy. Appl Energy. 2015;157:25-34.

36. Zirngast K, Čuček L, Kravanja Z, Novak Pintarič Z. Synthesis of biogas supply networks for the production of electricity and concentrated nitrogen fertilizer under uncertainty. Conference Proceedings, In: 14th Conference on Sustainable Development of Energy, Water and Environment Systems. SDEWES Centre, Dubrovnik; 2019. 
37. Lam HL, Klemeš JJ, Kravanja Z. Model-size reduction techniques for large-scale biomass production and supply networks. Energy. 2011;36(8):4599-608.

38. GAMS Development Corporation: GAMS - Documentation <gams.com/ latest/docs/gams.pdf>. Accessed 1 Dec 2019.

39. Bogataj M, Čuček L, Žula T, Kravanja S, Kravanja Z. Sustainable synthesis and optimization of engineering systems. WIT Transactions on The Built Environment. 2018;175:185-94.

40. European Commission: EU Emissions Trading System (EU ETS) <ec.europa. eu/clima/policies/ets_en>; Accessed 1 Dec 2019].

41. Lin B, Jia Z. Impacts of carbon price level in carbon emission trading market. Appl Energy. 2019;239:157-70.

42. Kravanja Z, Čuček L. Multi-objective optimisation for generating sustainable solutions considering total effects on the environment. Appl Energy. 2013; 101:67-80.

43. GreenDelta: The world's leading, high performance, open source Life Cycle Assessment software <openlca.org/>; Accessed 1 Dec 2019]. 2018.

44. ecoinvent: ecoinvent 3.1 <ecoinvent.org/database/older-versions/ ecoinvent-31/ecoinvent-31.html>; Accessed 1 Dec 2019].

45. GreenDelta: openLCA Nexus <nexus.openlca.org/downloads >; Accessed 1 Dec 2019]. 2019

46. European Commission; Directorate-General for Energy and Transport: Demonstration of an optimized system for biogas from biological waste and agricultural feedstock <managenergy.net/download/nr304.pdf >; Accessed 4 Jul 2011.

47. Vogtländer JG, Bijma A, Brezet HC. Communicating the eco-efficiency of products and services by means of the eco-costs/value model. J Clean Prod. 2002;10(1):57-67.

48. Sikdar SK. Sustainable development and sustainability metrics. AICHE J. 2003;49(8):1928-32.

49. Zirngast K, Kravanja Z, Novak Pintarič Z. A robust decomposition methodology for synthesis of flexible processes with many uncertainty parameters-application to HEN synthesis. Chem Biochem Eng Q. 2018;32(4): 401-11.

\section{Publisher's Note}

Springer Nature remains neutral with regard to jurisdictional claims in published maps and institutional affiliations.

Ready to submit your research? Choose BMC and benefit from:

- fast, convenient online submission

- thorough peer review by experienced researchers in your field

- rapid publication on acceptance

- support for research data, including large and complex data types

- gold Open Access which fosters wider collaboration and increased citations

- maximum visibility for your research: over $100 \mathrm{M}$ website views per year

At $\mathrm{BMC}$, research is always in progress.

Learn more biomedcentral.com/submissions 